\title{
A Specific Survival Response in Dopamine Neurons at Most Risk in Parkinson's Disease
}

\author{
Sachiko Murase and Ronald D. McKay \\ Laboratory of Molecular Biology, National Institute of Neurological Disorders and Stroke, National Institutes of Health, Bethesda, Maryland 20892
}

The specific expression of fibroblast growth factor 20 (FGF-20) in the adult substantia nigra and the association between FGF-20 mutations and Parkinson's disease provoked exploration of the function of this growth factor. We show by gain- and loss-of-function in vitro experiments that FGF-20 promotes survival and stimulates dopamine (DA) release in a calbindin-negative subset of cells that are preferentially lost in Parkinson's disease. FGF-20 selectively activates tyrosine hydroxylase in calbindin-negative neurons. In the adult substantia nigra, calbindin-negative neurons specifically express high levels of FGFR1 (FGF receptor 1). These data show that FGF signals to elevate DA levels and protect the specific midbrain neuron type at most risk in Parkinson's patients.

Key words: Parkinson's disease; fibroblast growth factor 20; dopamine; calbindin; midbrain; neurotrophic factor

\section{Introduction}

Parkinson's disease (PD), a common age-related degenerative disease, is associated with loss of DA neurons in the substantia nigra pars compacta $(\mathrm{SNpc})$ that play a critical role in voluntary movement (Dauer and Przedborski, 2003). The ability to overcome oxidative stress is essential for neuronal survival, and a decline in this function is a major cause of age-related neurodegenerative diseases (Prolla and Mattson, 2001). Because DA generates reactive oxygen species (ROS), DA neurons encounter higher levels of ROS than other neurons (Adams et al., 2001; Jenner, 2003). Oxidative stress induced by mitochondrial inhibition promotes cell death specific to DA neurons accompanied by Lewy body formation (Betarbet et al., 2000; Sherer et al., 2002). Genes linked to PD reduce dopamine transmission and oxidative stress. For example, $\alpha$-synuclein (Abeliovich et al., 2000) and DJ-1 (PAPK7) (Goldberg et al., 2005) downregulate DA release and uptake, respectively. Mutations in DJ-1 and PINK1 (PTENinduced kinase 1) compromise mitochondrial functions that secure the neurons from oxidative stress (Shen and Cookson, 2004). Environmental agents linked to increase PD risk also elevate oxidative stress (Betarbet et al., 2000). The identification of extracellular signals that reduce oxidative stress would be a valuable contribution to the emerging model of the sensitivity of midbrain DA neurons (Fahn and Sulzer, 2004).

Neurotrophic factors have a protective effect in animal models of Huntington's disease (HD) (Martinez-Serrano and Bjorklund, 1996), Alzheimer's disease (AD) (Tuszynski et al., 1990;

Received Feb. 7, 2006; revised Aug. 8, 2006; accepted Aug. 10, 2006

This work was supported by the Intramural Research Program of the National Institutes of Health-National Institute of Neurological Disorders and Stroke. We also thank the Michael J. Fox Foundation, the National Parkinson's Foundation, and the Tuchman Foundation for their support. We thank Dr. Charles Gerfen for critical reading and Drs. Raja Kittappa, Steve Poser, Jose Antonio Rodriguez-Gomez, and Ramesh Potla for their contributions to this work.

Correspondence should be addressed to Ronald D. McKay, 35 Convent Drive, MSC 4092, Bethesda, MD 20892. E-mail:mckay@codon.nih.gov.

DOI:10.1523/JNEUROSCI.2745-06.2006

Copyright $\odot 2006$ Society for Neuroscience $\quad$ 0270-6474/06/269750-11\$15.00/0
Backman et al., 1996), and amyotrophic lateral sclerosis (Acsadi et al., 2002; Mitchell et al., 2002; Wang et al., 2002). Disrupted neurotrophic factor function may also cause neurodegenerative disease. In Huntington's disease, the huntingtin protein regulates the transcription of BDNF in the cerebral cortex and disrupts the delivery of this factor to the striatum the proximal site of neuron degeneration (Zuccato et al., 2001; Baquet et al., 2004). Mutations in the amyloid precursor protein (APP) cause AD, and APP has been implicated in the anterograde axonal transport of the TrkA receptor for nerve growth factor (NGF) and the preferential loss of cholinergic neurons in the basal forebrain in this disease (Goldstein, 2003). These findings indicate that the impairment of neurotrophic factor signaling is a common feature of neurodegenerative disease. Elevated BDNF clearly delays disease progression in models of HD and clinical intervention using neurotrophic factors is underway in AD (Tuszynski et al., 2005).

In experimental models of $\mathrm{PD}$, brain-derived neurotrophic factor (BDNF) and glia cell-derived neurotrophic factor (GDNF) have been shown to play a role in the survival of DA neurons in the midbrain (Hyman et al., 1991; Lin et al., 1993). In animals, GDNF delivery to the striatum rescues midbrain DA neurons from cytotoxic stress (Choi-Lundberg et al., 1997, 1998; Connor et al., 1999). Although GDNF and the related protein neurturin are still the focus of gene delivery programs, a multicenter trial with GDNF was prematurely terminated because of the risk of adverse effects in other brain regions (Gill et al., 2003; Slevin et al., 2005). Fibroblast growth factor 2 (FGF-2) is also known to play a protective role for DA neurons in animal models of PD (Otto and Unsicker, 1990; Shults et al., 2000). However, in vitro studies suggest that the protective effect of FGF-2 depends on astrocytes (Knusel et al., 1990; Engele and Bohn, 1991; Suter-Crazzolara and Unsicker, 1996; Krieglstein et al., 1998a,b). These results show the need to more precisely define the protective action of growth factors on dopaminergic neurons.

FGF-20 is currently the only example of a neurotrophic factor in which genetic data support an involvement in PD (van der 
Walt et al., 2004). On the basis of genetic data alone, it is often hard to establish a causal link between mutation and the mechanism of disease. FGF-20 was originally cloned from an adult rat brain cDNA library and was shown to be preferentially expressed in adult SNpc neurons (Ohmachi et al., 2000). FGF-20 can activate its receptor, FGFR1c [a splice variant of FGF receptor 1 (FGFR1)], to initiate signaling in midbrain cultured cells (Ohmachi et al., 2003). Human FGF-20 has also been cloned, and its gene has been localized to the chromosome 8p22.3-p23 region (Kirikoshi et al., 2000). Polymorphisms in the FGF-20 gene are associated with PD (van der Walt et al., 2004). FGF-20 promotes both survival and DA release in calbindin-negative dopamine neurons because they specifically express FGFR1c. Calbindinnegative neurons are preferentially lost in PD (Fearnley and Lees, 1990; Yamada et al., 1990; Damier et al., 1999). Human genetic data suggest that compromised function of FGF-20 contributes to disease progression. This study identifies the protective response to FGFR1c in a subset of DA neurons as the basis of this effect.

\section{Materials and Methods}

Human recombinant FGF-20 was purchased from PeproTech (Rocky Hill, NJ). Human recombinant FGFR1b-Fc, FGFR1c-Fc, and $\alpha$ R-Fc were purchased from R \& D Systems (Minneapolis, MN). PD98059 and LY294002 were from Calbiochem (La Jolla, CA). 2-Deoxy-5-fluorouridine (FUDR), 6-OHDA, $\alpha$-methyl-p-tyrosine (AMPT), reserpine, nomifensine, quinpirole, sulpiride, NSD-1015 (3-hydroxybenzyl hydrazine), tetrodotoxin (TTX), D-2-amino-5-phosphonopentanoic acid (APV), 6-cyano-7-nitroquinoxaline-2,3-dione (CNQX), bicuculin, 4-aminopyridine (4-AP), anisomycin, dopamine (DA), and DAPI $\left(4^{\prime}, 6-\right.$ diamidino-2-phenyindole) were from Sigma-Aldrich (St. Louis, MO). 5-(and-6)-Carboxy-2', $7^{\prime}$-dichlorodihydrofluorescein diacetate (carboxy$\mathrm{H}_{2}$ DCFDA) was from Invitrogen (Eugene, OR). EZ-Link NHS-SS-Biotin [succinimidyl 2-(biotinamido)-ethyl-1,3'-dithiopropionate], protein A-Sepharose, and immobilized avidin were from Pierce (Rockford, IL). Rhodamine-conjugated streptavidin was from Jackson ImmunoResearch (West Grove, PA). Protease inhibitor mixture was purchased from Roche (Welwyn Garden City, UK).

Antibodies. Antibodies were used at the following dilutions: monoclonal mouse anti-calbindin antibody, anti-tyrosine hydroxylase (TH) antibody, anti- $\alpha$-tubulin antibody, and polyclonal rabbit anti-FGFR1 antibody (Sigma-Aldrich), 1:200, 1:500, 1:10,000, and 1:500, respectively; polyclonal rabbit and sheep anti-TH antibodies, polyclonal rabbit vesicle monoamine transporter-2 (VMAT2; Pel-Freez Biologicals, Rogers, AR), 1:500; polyclonal rabbit anti-phosphorylated (phospho) Ser-19, Ser-31, Ser-40 TH antibodies (Zymed, San Francisco, CA), 1:100, 1:500, and 1:100, respectively; monoclonal rat anti-dopamine transporter (DAT; Biogenesis, Kingston, NH), 1:200; monoclonal mouse anti-Hu (Invitrogen), 1:100; polyclonal rabbit anti-phospho p40/p42 mitogen-activated protein kinase (MAPK) antibody, 1:500; anti-phospho Ser-473 Akt antibody, 1:500; anti-cleaved caspase-3 antibody, 1:200; anti-phosho Ser-166 mouse double minute 2 (MDM2) antibody, 1:200; anti-phospho stressactivated protein kinase/Jun N-terminal kinase (SAPK/JNK), 1:200; antiphospho p38, 1:500 (Cell Signaling, Danvers, MA); polyclonal rabbit anti-phospho Ser-136 Bad, 1:200; polyclonal rabbit anti-Bax antibody, 1:200; anti-p53 antibody, 1:200 (Santa Cruz Biotechnology, Santa Cruz, CA); monoclonal mouse anti-cytochrome $c$ antibody, 1:200 (BD Biosciences PharMingen, San Diego, CA); Alexa Fluor488 (568, or 647)conjugated goat anti-mouse (rabbit or sheep) IgG antibodies (Invitrogen), 1:200; HRP-conjugated goat anti-mouse, rabbit, and rat IgG antibodies (Invitrogen), 1:2000; biotinylated rabbit anti-rat IgG antibody (Vector Laboratories, Burlingame, CA), 1:200.

Dissociated cultured neurons. Astrocyte beds were prepared from embryonic day 18 (E18) rat ventral midbrain. The cells were treated with papain (Worthington Biochemicals, Freehold, NJ), dissociated with a flame polished Pasteur pipette, then plated at a density of $3 \times 10^{4}$ cells/ $\mathrm{cm}^{2}$ on coverslips coated with Vitrogen (Cohesion, Palo Alto, CA) and
poly-D-lysine (Sigma-Aldrich) and cultured in modified MEM (82-0234 DJ; Invitrogen) with $10 \%$ fetal bovine serum (FBS) for $14 \mathrm{~d}$ in $10 \% \mathrm{CO}_{2}$ at $37^{\circ} \mathrm{C}$.

Neurons were prepared from E14 rat ventral midbrain and dissociated as described above, then plated at a density of $8 \times 10^{4} \mathrm{cells} / \mathrm{cm}^{2}$ on the astrocyte bed. The primary neuron cultures were grown in modified MEM with $5 \%$ horse serum and $1 \%$ FBS in $10 \% \mathrm{CO}_{2}$ at $37^{\circ} \mathrm{C}$. For gliafree cultures, cells were plated at a density of $1.6 \times 10^{5} \mathrm{cells} / \mathrm{cm}^{2}$ on coverslips described above, and cultured in Neurobasal and B27 (Invitrogen) with $5 \% \mathrm{FBS}$ and FUDR for $12 \mathrm{~d}$ in $10 \% \mathrm{CO}_{2}$ at $37^{\circ} \mathrm{C}$. All of the experiments were done in Neurobasal and B27 except that glia-free cultures were incubated overnight in Neurobasal (without B27). Numbers of $\mathrm{TH}^{+}$and $\mathrm{Hu}^{+}$(neuron-specific protein) neurons were unaffected by overnight incubation without B27.

Organotypic slice culture. Coronal sections of rat postnatal day 1 midbrain (400 $\mu \mathrm{m}$ thickness) were placed on Millicell culture plate insert (Millipore, Bedford, MA), and cultured for $10 \mathrm{~d}$ with slice culture medium (25\% MEM, 2 mM Glutamax, 0.0435\% sodium bicarbonate, 25\% HBSS, $25 \%$ horse serum, $\mathrm{pH} 7.2)$ in $5 \% \mathrm{CO}_{2}$ at $37^{\circ} \mathrm{C}$. Slices were then incubated with Neurobasal and B27 overnight before the experiments.

Immunostaining and image analysis. Cells were fixed with $4 \%$ sucrose and $4 \%$ paraformaldehyde (PFA) in PBS on ice for $20 \mathrm{~min}$, followed by methanol on ice for $10 \mathrm{~min}$. Blocking was performed in $4 \%$ normal goat serum (NGS) and $0.1 \%$ Triton X-100 in PBS at room temperature for 30 min. Incubation with the primary and secondary antibodies was in the blocking solution for $2 \mathrm{~h}$ at room temperature.

Fluorescent images were obtained with a Zeiss (Oberkochen, Germany) fluorescent microscope (Axiovert 100) equipped with a $10 \times$ lens. For cell survival experiments, both imaging and analysis were done blind. Eight to 10 images were taken from each coverslip. More than three coverslips from more than two preparations were used for each experimental group. Activated DA neurons were visualized by phospho-Ser-31 TH (Witkovsky et al., 2004). For analyses of cleaved-caspase-3, phosphoSer-31 TH and phospho-extracellular signal-regulated kinase $1 / 2$ (Erk1/2) numbers per coverslip (10 images taken with $10 \times$ lens were combined) were compared. More than two coverslips from two different preparations were used. For phospho-Ser-31 TH, 21 cells per coverslip on average were found in the control; for phospho-Erk1/2, 14 DA neurons per coverslip were found in the control.

For adult midbrain slice staining, the brains fixed with $4 \%$ PFA overnight were incubated in $20 \%$ sucrose for $2 \mathrm{~d}$. Coronal sections were made using a cryostat at $40 \mu \mathrm{m}$ thickness. The slices were then blocked with $4 \%$ NGS, $0.1 \%$ Triton X-100 in PBS for 30 min. Incubation with primary and secondary antibodies was done in the blocking solution. For organotypic slices, 4\% PFA was used for fixation (30 $\mathrm{min}$ at room temperature). Blocking solution containing $1 \%$ BSA and $0.1 \%$ Triton X-100 in PBS was used. Slices were washed with PBS three times after the incubation with the antibodies.

Fluorescent images of slices were obtained with a Zeiss confocal microscope (LSM-510) equipped with a $10 \times$ or a $25 \times$ lens. $Z$-stacked images from eight sections ( $1 \mu \mathrm{m}$ interval) were used for the analysis. For organotypic slice experiments, $>2$ slices per conditions were used for one experiment. The experiments were repeated using three independent preparations.

Student's $t$ test was used for statistical comparisons. The mean \pm SEM was plotted.

HPLC analysis of catecholamines. For measurement of DA release, neurons were incubated in $0.5 \mathrm{ml} /$ one 24-well of modified Krebs' HEPES buffer (MKB) [containing the following (in $\mathrm{mM}$ ): $127 \mathrm{NaCl}, 5 \mathrm{KCl}, 1.3$ $\mathrm{NaH}_{2} \mathrm{PO}_{4}, 1.2 \mathrm{MgSO}_{4}, 2.5 \mathrm{CaCl}_{2}, 10$ glucose, 15 HEPES, pH 7.4] for 15 min in $10 \% \mathrm{CO}_{2}$ at $37^{\circ} \mathrm{C}$. For high $\mathrm{K}^{+}$stimulation, $50 \mathrm{~mm} \mathrm{KCl}$ buffer containing $82 \mathrm{~mm} \mathrm{NaCl}$ instead of $127 \mathrm{~mm}$ was used. The buffer was collected and kept with the stabilizing solution ( $88 \mu \mathrm{l}$ of $85 \%$ orthophosphoric acid and $4.4 \mathrm{mg}$ of metabisulfide) at $-80^{\circ} \mathrm{C}$. Catecholamines were extracted from the medium by a sample clean up column (Chromsystem). For measurements of DA and L-DOPA contents, the samples were harvested in $300 \mu \mathrm{l}$ per one 24 -well of stabilizing solution $(0.1 \mathrm{M}$ perchloric acid, $0.02 \%$ EDTA, $1 \%$ ethanol), and sonicated on ice. The supernatant collected after centrifugation at $14,000 \mathrm{rpm}$ for $10 \mathrm{~min}$ at $4^{\circ} \mathrm{C}$ was 
applied to high-pressure liquid chromatography (HPLC). The samples were analyzed with a Hewlett Packard (Palo Alto, CA) Series 1050 HPLC system equipped with a reverse-phase $\mathrm{C} 18$ column ( $3 \mu \mathrm{m}$ particle size, $80 \times 4.6 \mathrm{~mm}$ dimension; ESA, Chelmsford, MA) in an MD-TM mobile phase (ESA). The oxidative potential of the analytical cell (Mod 5011; ESA) was set at $+325 \mathrm{mV}$. HP Chemistation was calibrated using standards before measuring peak area to quantify catecholamines. Data represent the amounts of catecholamines per one 24 well of the cultures. Student's $t$ test was used for statistical comparisons. The mean \pm SEM was plotted.

Western blotting. Neurons were incubated in $0.5 \mathrm{ml}$ per one 24 well of Neurobasal and B27 overnight. Ten microliters of Neurobasal containing FGF-20 were added to each well (final concentration, $10 \mathrm{ng} / \mathrm{ml}$ ). After incubation at $37^{\circ} \mathrm{C}$ for $10 \mathrm{~min}$ (or the indicated time), the samples were collected with $60 \mu \mathrm{l}$ per one 24 well of SDS loading buffer, and boiled for $5 \mathrm{~min}$, then applied to a $4-15 \%$ gradient SDS gel (Bio-Rad, Hercules, $\mathrm{CA})$. The proteins were transferred to a nitrocelluose membrane. The blocking was performed with $4 \%$ skim milk in PBS for $30 \mathrm{~min}$. The primary and secondary antibodies were diluted in the blocking solution. After overnight incubation with primary antibody at $4^{\circ} \mathrm{C}$, the membrane was washed three times with Tris-buffered saline with Tween 20, and incubated with secondary antibody for $2 \mathrm{~h}$ at room temperature. The proteins were visualized with SuperSignal West Pico Chemiluminescent Substrate (Pierce), and detected with a BioChemi System (UVP BioImaging Systems, Upland, CA). The mean \pm SEM was plotted.

Cell surface biotinylation. Cells were treated with $10 \mathrm{ng} / \mathrm{ml} \mathrm{FGF-20} \mathrm{for}$ $1 \mathrm{~h}$ before surface labeling. Cells were washed two times with PBS, followed by incubation with $1 \mathrm{~mm}$ EZ-Link NHS-SS-Biotin on ice for 30 min. Biotinylating reagents were removed by washing three times with PBS before they were lysed on ice for $15 \mathrm{~min}$ with $60 \mu \mathrm{l}$ of lysis buffer ( 50 mм Tris-HCl, pH 7.4, $150 \mathrm{~mm} \mathrm{NaCl}, 1 \% \mathrm{NP}-40$, and protease inhibitor mixture) per well. The lysates were centrifuged at $14,000 \times g$ for $5 \mathrm{~min}$ at $4^{\circ} \mathrm{C}$, then incubated with $10 \%(\mathrm{v} / \mathrm{v})$ of prewashed protein A-Sepharose or immobilized avidin for $2 \mathrm{~h}$ at $4^{\circ} \mathrm{C}$. The beads were washed three times with lysis buffer before the absorbed proteins were eluted by boiling for 5 min with SDS loading buffer.

Detection of $\mathrm{H}_{2} \mathrm{O}_{2}$ production. To detect $\mathrm{H}_{2} \mathrm{O}_{2}$, cells were incubated in HBS containing $10 \mu \mathrm{M}$ carboxy- $\mathrm{H}_{2}$ DCFDA for $30 \mathrm{~min}$. Cells were then, fixed with PFA and briefly incubated with $0.1 \%$ Triton X-100 in PBS. Blocking and immunostaining with TH were performed with PBS containing 4\% NGS without Triton X-100.

\section{Results}

\section{Maturation of DA neurons in vitro}

Neuron-astrocyte cocultures have been used to analyze the cytotoxic effects of oxidative stress in DA neurons (Fon et al., 1997; Larsen et al., 2002). In this study, dissociated primary neurons from ventral midbrain E14 were cultured with ventral midbrain E18 astrocytes and the number of surviving neurons measured over 3 weeks of growth. The number of neurons in culture with and without fetal calf serum was measured to determine whether there was a transient period of cell death. The total number of neurons, including DA neurons, declined during the first $10 \mathrm{~d}$ and then became stable (Fig. 1a). During this period, DA neurons progressively acquired complex morphologies and by $20 \mathrm{~d}$ in vitro (DIV20), the processes of $\mathrm{TH}$-expressing DA neurons showed distributions of both presynaptic and postsynaptic marker proteins (synaptophysin and PSD95, respectively) suggesting the formation of synapses (Fig. 1b,c).

DA function is regulated by synaptic proteins controlling vesicular localization and reuptake. Pharmacological probes were used to determine the stage when the cells in culture show mature synaptic properties. At DIV7, extracellular DA was increased by reserpine, an inhibitor of VMAT2 and reduced by nomifensine, an inhibitor of the DAT (Fig. 1d). A mixture of drugs that inhibit neuronal activity (TTX, APV, CNQX, and bicuculline) did not affect extracellular DA. Quinpirole and sulpiride, an agonist and
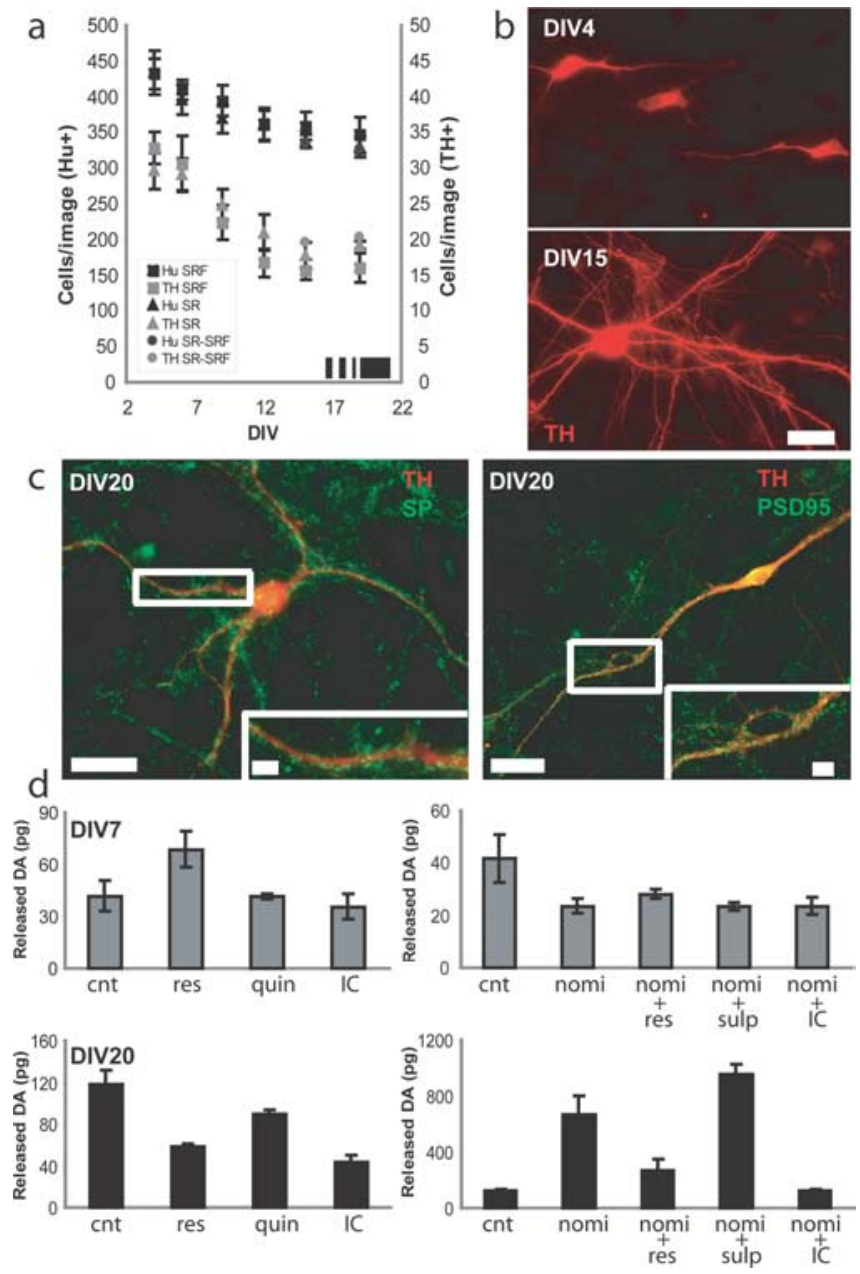

Figure 1. Development of DA neurons in dissociated ventral midbrain culture. $\boldsymbol{a}$, Neurons including DA neurons go through natural cell death. Shown are numbers of cells/image from the cultures without serum (SRF; Neurobasal and B27) $\left(\mathrm{Hu}^{+}\right.$, black square; $\mathrm{TH}^{+}$, gray square), from the cultures with serum (SR; modified MEM) $\left(\mathrm{Hu}^{+}{ }^{+}\right.$, black triangle; $\mathrm{TH}^{+}$, gray triangle), and the cultures switched from SR to SRF at DIV12 $\left(\mathrm{Hu}^{+}{ }^{+}\right.$, black circle; $\mathrm{TH}^{+}{ }^{+}$, gray circle; $\left.n=40\right)$. All of the experiments were done after DIV19 except for the long incubation with FGFR-FC (DIV16). $\boldsymbol{b}$, Extension of processes. DA neurons are stained with anti-TH antibody. Top, DIV4; bottom, DIV15. Scale bar, $20 \mu \mathrm{m}$. c, Formation of synaptic structure. By DIV20, processes of DA neurons (TH, red) are well colocalized with both pre- [synaptophysin (SP), green, left] and post(PSD95, green, right) synaptic markers. Scale bars, $50 \mu \mathrm{m}$. Insets are magnified images (scale bars, $5 \mu \mathrm{m}$ ). d, DA release from young (top) and mature (bottom) DA neurons. cnt, Control; res, $1.5 \mu \mathrm{m}$ reserpine; quin, $5 \mu \mathrm{m}$ quinpirole; IC, inhibitor cocktail (1 $\mu \mathrm{m}$ TTX, $100 \mu \mathrm{M}$ APV, $50 \mu \mathrm{m}$ CNQX, $30 \mu \mathrm{m}$ bicuculin); nomi, $5 \mu \mathrm{m}$ nomifensine; sulp, $5 \mu \mathrm{m}$ sulpiride. $n=4$. Error bars indicate SE.

an antagonist for the $\mathrm{D}_{2}$ subtype of DA receptor, did not change extracellular DA. These data suggest that at this stage of maturation, DA neurons express functional VMAT2 and DAT, but neuronal activity has a small role in extracellular DA.

At DIV20, DA release was three times higher than DIV7 and was reduced by the neuronal activity inhibitor mixture, indicating that neuronal activity-regulated synaptic release is the major source of DA release (Fig. 1d). Reserpine reduced and nomifensine increased DA levels. Quinpirole inhibits the $\mathrm{D}_{2}$ autoreceptor (Kuzhikandathil et al., 1998) and, by DIV20, inhibits DA levels. The effects of nomifensine were enhanced by reserpine and by sulpiride, an antagonist for $\mathrm{D}_{2}$ receptor. These results show that at DIV20, cultured neurons release and reuptake DA using physiologically relevant mechanisms. This system, where DA neurons in culture differentiate to a stage where DA metabolism 
a

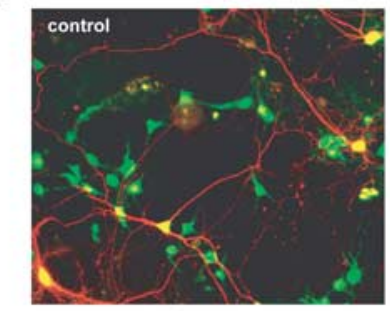

b
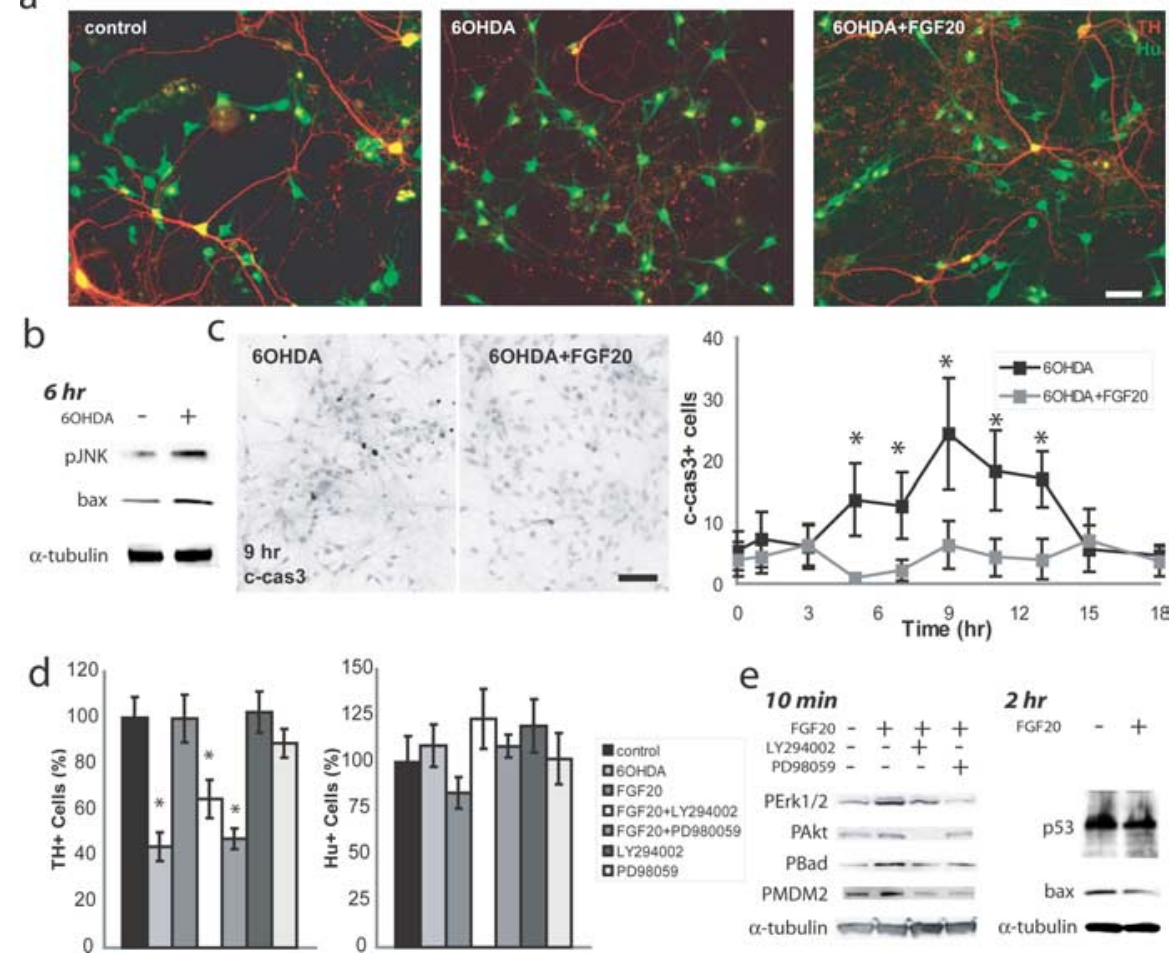

Figure 2. 6-OHDA lesion rescued by FGF-20. $\boldsymbol{a}$, Immunostaining with TH (red) and Hu (green). 6-0HDA treatment causes DA neuron-specific loss, which is rescued by FGF-20. Thirty millimolars 6-OHDA in PBS was freshly prepared and filtered immediately

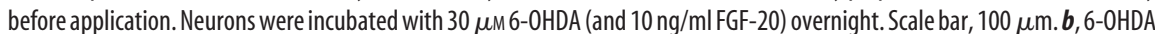
induces stress response. Cells were incubated with $30 \mu \mathrm{m} 6-0 \mathrm{HDA}$ for $6 \mathrm{~h}$. c, Cleaved-caspase-3 immunostaining (left) when incubated for $9 \mathrm{~h}$ with 6-0HDA (and FGF-20). Scale bar, $50 \mu \mathrm{m}$. Shown are numbers of cleaved-caspase- ${ }^{+}$cells after incubating with $30 \mu \mathrm{m} 6-0 \mathrm{HDA}$ (and $10 \mathrm{ng} / \mathrm{mlFGF}-20)$ for the indicated time (right) $(n=10){ }^{*} p<0.05$. $\boldsymbol{d}$, Effect ofFGF-20 and contribution of MAPK and PI3 kinase. Neurons were incubated with $50 \mu \mathrm{M}$ PD98059 or $25 \mu \mathrm{M}$ LY294002 $(n=30)$. ${ }^{*} p<0.05$. e, FGF-20 activates both MAPK and PI3K pathways in ventral midbrain culture, and protects mitochondria. $\alpha$-Tubulin was blotted as a loading control. To minimize the contribution of astrocytes, the glia-free cultures were used. Error bars indicate SE. a

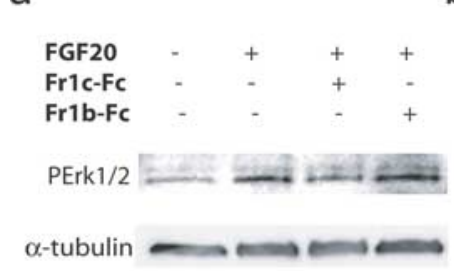

C

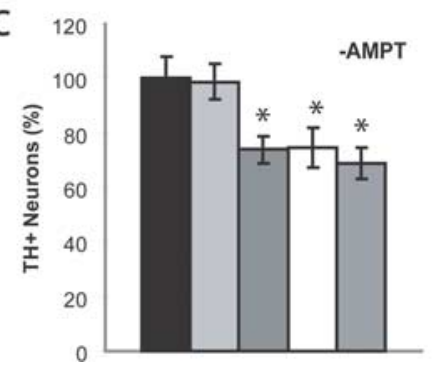

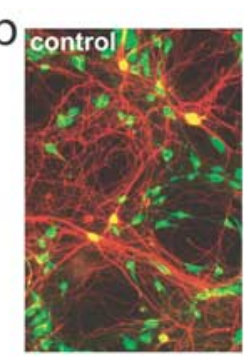

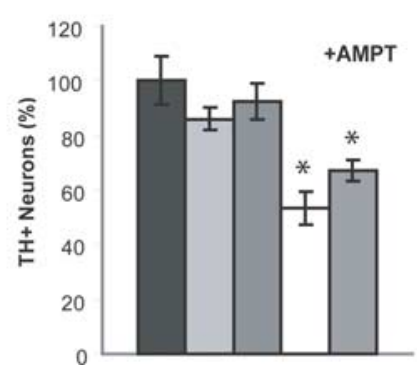

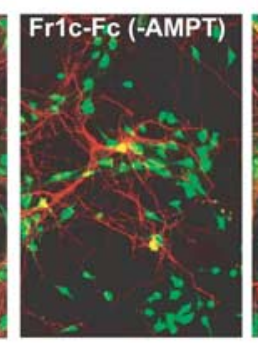
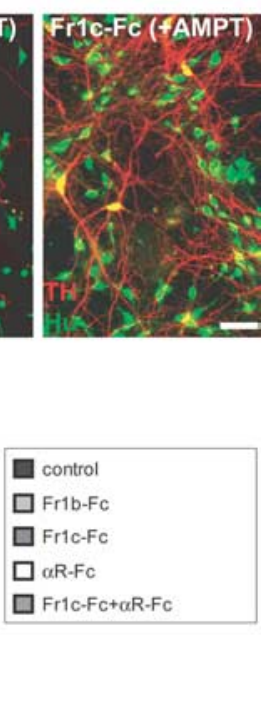

Figure 3. Role of endogenous activation of FGFR1c. $\boldsymbol{a}$, FGFR1c-Fc selectively inhibits PErk1/2 activation by FGF-20. Fc-chimeric proteins were preincubated with FGF- 20 at $37^{\circ} \mathrm{C}$ for $2 \mathrm{~h}$ before applied to cultured neurons. Final concentrations of FGF- 20 and Fc-chimeric protein were $10 \mathrm{ng} / \mathrm{ml}$ and $200 \mathrm{ng} / \mathrm{ml}$, respectively. $\boldsymbol{b}$, Cell death of DA neurons induced by FGFR1c-Fc. Neurons were incubated for $4 \mathrm{~d}$ with $100 \mathrm{ng} / \mathrm{ml}$ FGFR1c-Fc in the presence or absence of $500 \mu \mathrm{M}$ AMPT. Half of the medium was changed everyday. Immunostaining with TH (red) and Hu (green) is shown. Scale bar, $100 \mu \mathrm{m}$. c, Effect of Fc-chimeric proteins. Incubation with $100 \mathrm{ng} / \mathrm{ml} \mathrm{Fc-chimeric} \mathrm{proteins} \mathrm{with} \mathrm{or} \mathrm{without} 500 \mu \mathrm{M}$ AMPT for $4 \mathrm{~d}(n=40) .{ }^{*} p<0.05$. Error bars indicate SE. is mature and the number of neurons is stable, was used to analyze the effects of oxidative stress and neurotrophic mechanisms on neuronal loss and survival.

\section{FGF-20 rescues mature DA neurons from the toxicity of 6-OHDA}

6-OHDA is efficiently taken up by the DAT and causes oxidative stress, and 6-OHDA is widely used to lesion DA neurons in vitro and in vivo (Ungerstedt, 1971; Ding et al., 2004). In cultured midbrain neurons, $6 \mathrm{~h}$ of exposure to 6-OHDA activated the SAPK/JNK, and the proapoptotic protein Bax (Fig. 2b). A wave of caspase- 3 positive cells with a peak at $9 \mathrm{~h}$ was observed after the toxin was applied, indicating that apoptosis was induced (Fig. 2c). Coapplication of $10 \mathrm{ng} / \mathrm{ml}$ FGF-20 blocked the effect of 6-OHDA (Fig. 2c). A lower concentration of FGF-20 $(50 \mathrm{pg} / \mathrm{ml})$ did not rescue the cells $(n=15$; $p=0.545$ ). Double immunostaining with antibodies against $\mathrm{TH}$ and $\mathrm{Hu}$, a neuron specific protein, showed that DA neurons are specifically sensitive to 6-OHDA (Fig. $2 a, d)$.

FGF ligands signal through tyrosine kinase receptors that activate a downstream phosphorylation cascade including Akt and Erk (Kouhara et al., 1997; Ong et al., 2001). FGF-20 induced Akt and Erk activation and induced phosphorylation of the proapoptotic protein Bad at Ser-136 (Fig. 2e). FGF treatment phosphorylates MDM2 at Ser-166, which is known to promote proteasomal degradation of p53 (Grossman et al., 1998). Decreased levels of intact p53 were observed $2 \mathrm{~h}$ after FGF application (Fig. 2e). The ability of FGF-20 to rescue DA neurons from 6-OHDA toxicity was blocked by drugs that inhibit phosphatidylinositol 3 kinase (PI3K) and MAP kinase, and inhibition of PI3K blocked FGF-20-induced Erk activation, vice versa (Fig. 2d). Kinase inhibition alone did not affect the survival of neurons. These data show that FGF-20 acting through known second messengers supports DA neuron survival in response to an external toxin.

\section{An endogenous FGF signal supports} neurons from a DA-dependent stress The role of endogenous FGF in neuronal survival was investigated using a chimeric protein composed of the extracellular domains of FGFR1c fused with the immunoglobulin constant region (FGFR1c-Fc). To confirm that this synthetic protein had the ability to inhibit the binding of FGF-20, the activation of MAPK by FGF-20 was inhibited by FGFR1c-Fc (Fig. 3a). Preincu- 
bation with another splice variant FGFR1b-Fc that contains a different III domain critical for ligand recognition (Isacchi et al., 1990; Yeh et al., 2003) did not inhibit MAPK activation (Fig. 3a).

A loss of DA neurons was observed when midbrain neurons were incubated with FGFR1c-Fc for $4 \mathrm{~d}$ (Fig. $3 b, c$ ). The incubation with FGFR1b-Fc did not change the numbers of DA neurons (Fig. $3 c)$. A receptor-immunoglobulin protein for the GDNF receptor $(\alpha \mathrm{R}-\mathrm{Fc})$ also caused a loss of DA neurons but no additional loss was observed when both the chimeric proteins were applied together (Fig. $3 c$ ). None of these manipulations affected the total number of neurons (data not shown). These data indicate that endogenous FGF is required to maintain the survival of the subset of DA neurons.

A competitive inhibitor of TH, AMPT, was used to determine whether DA levels contribute to the neuron death induced by growth factor competition. A $2 \mathrm{~h}$ incubation with AMPT decreased extracellular DA levels to $21.2 \pm 2.4 \%(n=4)$ of the control. When AMPT was coapplied with FGFR1c-Fc there was no cytotoxic effect, while the effect of $\alpha \mathrm{R}-\mathrm{Fc}$ was unchanged (Fig. $3 c$ ). Treatment with AMPT alone did not change the numbers of either DA or total neurons $(103.7 \pm 12.0$ and $111.5 \pm$ $9.7 \%$ of the control, respectively; $n=40$ ). Although only a small amount was detected, AMPT was reported to be converted to $\alpha$-methyl-p-tyramine (Dougan et al., 1983). Because tyramine undergoes turnover through monoamine oxidase and produces ROS (Juorio and Boulton, 1982; Hauptmann et al., 1996), we tested whether the cells were under stress when treated with AMPT. Neither SAPK/JNK nor p38, kinases known to be activated by stress (Ichijo, 1999), were activated by AMPT (Fig. 4e). This result indicates that an endogenous FGF signal supports survival from stress influenced by DA levels.

FGF-20 rescues neurons from stress induced by cytosolic DA DA localization is controlled by two transporters: DAT is a plasma membrane that recovers extracellular DA into the cytoplasm, and VMAT2 generates high concentrations of DA in synaptic vesicles (Henry et al., 1994; Wang et al., 1997; Mortensen and Amara, 2003). Inhibitors of DAT and VMAT2 regulate DA levels appropriately in neurons at DIV20 (Fig. 1d). Here, we use pharmacological manipulations to explore the toxicity of endogenous DA.

When young neurons (DIV7) were incubated overnight with the VMAT2 inhibitor reserpine $(1.5 \mu \mathrm{M})$, neuron numbers were not affected. In contrast, a significant loss of DA neurons was observed when the mature cultures (DIV20) were incubated with reserpine (Fig. 4a,b). No loss was observed by the inhibition of DAT with nomifensine (Fig. 4b). Coapplication of nomifensine blocked the effect of reserpine (Fig. $4 a, b$ ). When DA synthesis was biotinylation. Error bars indicate SE. b
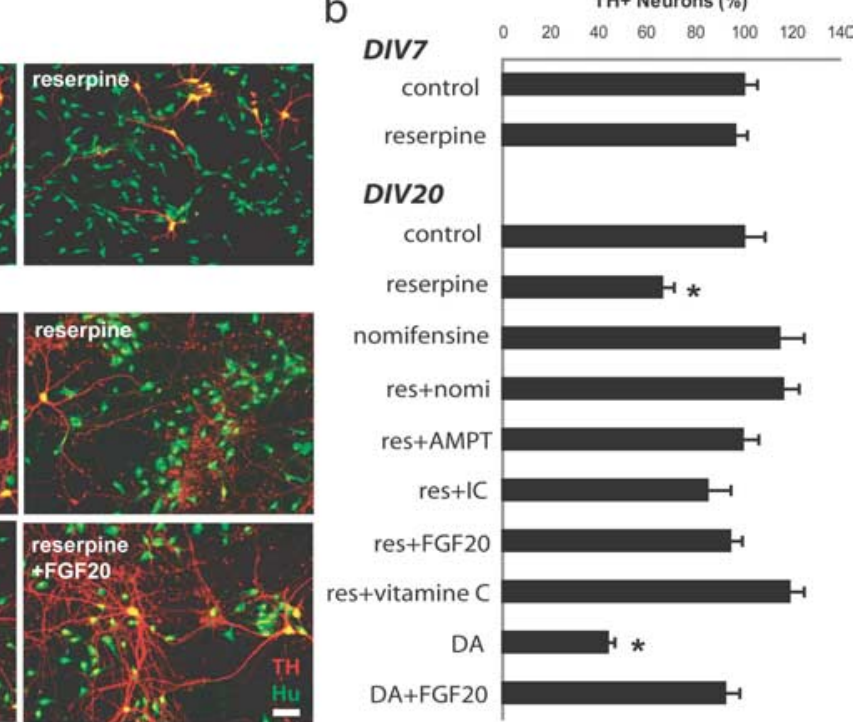

d
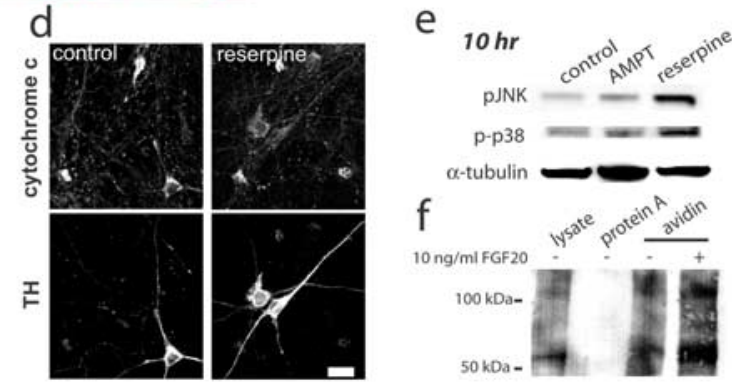

Figure 4. DA-induced toxicity rescued by FGF-20. $\boldsymbol{a}$, Inhibition of VMAT2 caused loss of DA neurons in mature but not young cultures. Neurons were incubated overnight with $1.5 \mu \mathrm{m}$ reserpine (and $10 \mathrm{ng} / \mathrm{ml} \mathrm{FGF-20).} \mathrm{Shown} \mathrm{are} \mathrm{representative} \mathrm{images}$ TH (red) and Hu (green) of control, $1.5 \mu \mathrm{m}$ reserpine, $1.5 \mu \mathrm{m}$ reserpine plus $5 \mu \mathrm{m}$ nomifensine, and $1.5 \mu \mathrm{m}$ reserpine plus $10 \mathrm{ng} / \mathrm{ml} \mathrm{FGF-20} \mathrm{overnight-treated} \mathrm{neurons.} \mathrm{Scale} \mathrm{bar,} 100 \mu \mathrm{m} . \boldsymbol{b}$, Neurons were incubated overnight with $1.5 \mu \mathrm{m}$ reserpine

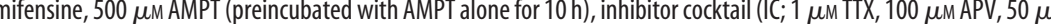

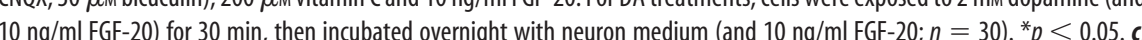

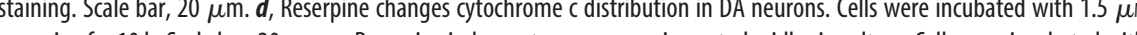
rpine for $10 \mathrm{~h}$. Scale bar, $20 \mu \mathrm{m}$. $\boldsymbol{e}$, Reserpine induces stress response in ventral midbrain culture. Cells were incubated with $1.5 \mu \mathrm{m}$ reserpine or $500 \mu \mathrm{m}$ AMPT for $10 \mathrm{~h}$. $f$, Surface labeling of DAT. Cells were treated with $10 \mathrm{ng} / \mathrm{ml} \mathrm{FGF-20}$ for $1 \mathrm{~h}$ before

inhibited by AMPT, reserpine showed no toxicity (Fig. 4b). Blockade of neuronal activity also blocked the loss of DA neurons. Ascorbic acid (vitamin C) blocked the effect of reserpine, indicating the toxicity is caused by oxidation (Fig. $4 b$ ). None of these manipulations affected total number of neurons (data not shown). These data suggest that VMAT2 function is required to protect neurons from DA that is released by activity and taken back into the cell by DAT.

When cytosolic DA is higher than extracellular DA, the DAT can act in a reverse manner allowing DA to leave the cell (Sulzer et al., 2005). However, there are mechanisms that buffer DA levels. Direct measurements of cytosolic DA in chromaffin cells demonstrate that catecholamine levels were only transiently elevated by L-DOPA treatment and returned to the basal level within $10 \mathrm{~min}$ (Mosharov et al., 2003). To define DA levels directly, the DA content in neurons was measured in the presence of reserpine. DA content was decreased by 15 min of incubation with reserpine ( $32 \%$ of control; $n=4)$. Nomifensine did not influence the effect of reserpine on DA content ( $30 \%$ of control; $p=0.34 ; n=4)$. These results show that reserpine reduces total DA and that the 
a
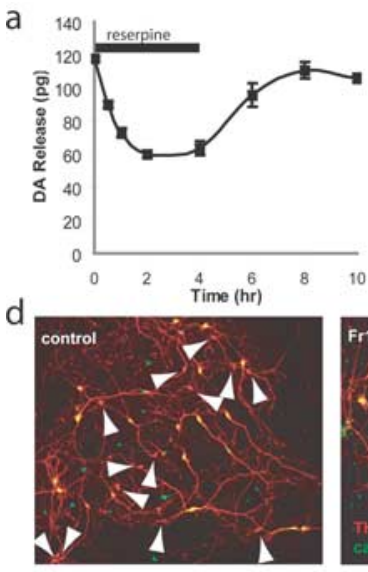
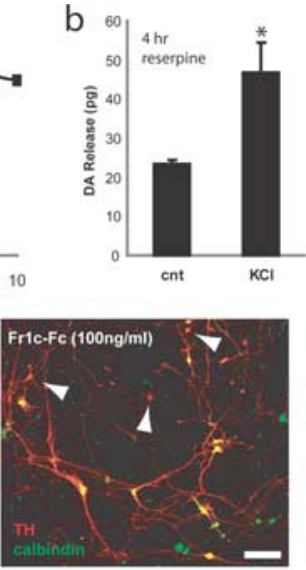
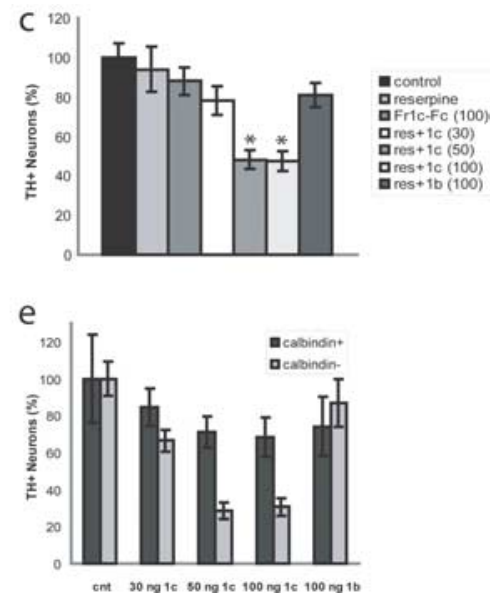

Figure 5. Short-term treatment with reserpine and FGFR1c-Fc causes loss of DA neurons. $\boldsymbol{a}$, Effect of reserpine on DA release. The cultured neurons were incubated with $1.5 \mu \mathrm{m}$ reserpine for $4 \mathrm{~h}$ (bar). DA release decreased rapidly after the application of 1.5 $\mu \mathrm{m}$ reserpine, and recovered after the removal of reserpine $(n=4) . \boldsymbol{b}, \mathrm{DA}$ release is stimulated by high $\mathrm{K}^{+}$after $4 \mathrm{~h}$ of incubation with reserpine ( $n=4 ; p=0.026$ ). c, FGFR1c-Fc but not FGFR1b-Fc promotes DA neuron cell death induced by cytosolic DA in a dose-dependent manner. Neurons were incubated for $4 \mathrm{~h}$ with $1.5 \mu \mathrm{m}$ reserpine and the indicated concentrations of FGFR1c-Fc, then incubated with the medium overnight $(n=30) .{ }^{*} p<0.05 . \boldsymbol{d}$, Immunostaining of TH (red) and calbindin (green) is shown. Number of calbindin ${ }^{-}$DA neurons is decreased by $4 \mathrm{~h}$ treatment with1.5 $\mu \mathrm{m}$ reserpine and $100 \mathrm{ng} / \mathrm{ml} \mathrm{FGFR1c-Fc} \mathrm{(right),} \mathrm{as}$ compared with control (left). Scale bar, $100 \mu \mathrm{m}$. Arrowheads, Calbindin ${ }^{-}$DA neurons. $e$, Calbindin ${ }^{-}$DA neurons are sensitive to

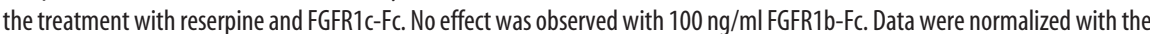
total number of DA neurons in the control $(n=30)$. Error bars indicate SE.

DAT inhibitor does not cause a chronic elevation of DA. A transient increase in extracellular DA applied exogenously also caused neuron loss (Fig. 4b). These data suggest that DA entering the cells through DAT is the source of toxicity and show that FGF-20 rescued DA neurons from reserpine treatment and DA toxicity (Fig. 4b).

Previous studies suggest that the protective effect of FGF-2 on DA neurons was mediated by astrocytes (Knusel et al., 1990; Engele and Bohn, 1991). DA neurons in glia-free culture were also susceptible to 6-OHDA and DA treatments, but not to reserpine treatment (data not shown). In the absence of glia, neurons do not survive $>2$ weeks and may not mature adequately to show the toxicity of reserpine.

To test whether reserpine indeed causes oxidative stress in mature DA neurons, $\mathrm{H}_{2} \mathrm{O}_{2}$ production was detected using carboxy- $\mathrm{H}_{2}$ DCFDA. After $6 \mathrm{~h}$ incubation with reserpine, the signal was notably increased in some of the DA neurons (Fig. $4 \mathrm{c}$ ). In $10 \mathrm{~h}$, some of the DA neurons changed distribution of cytochrome c from a strongly punctated pattern as seen in the control to a scattered pattern (Fig. 4d). Activation of SAPK/JNK and p38 was observed (Fig. 4e). These results suggest that DA neurons die from oxidative stress and subsequent mitochondrial damage by reserpine treatment.

Reduction of DAT function would be a possible mechanism for FGF-20 protection. To test this idea, we analyzed DAT by cell surface biotinylation both in FGF-20 treated and nontreated culture. When blotted with anti-DAT antibody, two bands were detected from the lysates at 55 and $110 \mathrm{kDa}$ (Fig. 4f). When the surface proteins were labeled by biotinylation, both the bands were enriched in the proteins bound to avidin, but not to protein A-Sepharose beads (Fig. 4f). FGF-20 treatment increased the amount of surface DAT (Fig. $4 f$ ). MAPK and PI3K are known to upregulate the surface expression of DAT and enhance DA uptake (Carvelli et al., 2002; Moron et al., 2003). FGF-20 activates both of these kinases (Fig. 2e) and the surface labeling data suggest that FGF-20 elevates rather than reduces the surface expression of DAT.
This result suggests that FGF-20 blocks the oxidative damage caused by cytosolic DA taken up by DAT.

The interaction between FGF signaling and VMAT function was further explored by defining a time when reserpine first altered DA levels. Extracellular DA levels fell rapidly for the first $2 \mathrm{~h}$ when cells were exposed to reserpine and then remained stable for an additional $2 \mathrm{~h}$ of treatment. The level of extracellular DA recovered almost completely after the drug was washed out (Fig. $5 a$ ). In cells treated with reserpine for $4 \mathrm{~h}$, DA release was stimulated by high $\mathrm{K}^{+}$, indicating that the vesicular pool of DA was present (Fig. 5b). This short exposure to reserpine had no effect on cell number, but treatment with reserpine and FGFR1c-Fc resulted in DA neuron death (Fig. $5 c$ ). The death of DA neurons was dependent on the dose of FGFR1c-Fc showing that endogenous FGF signals promote survival from toxicity induced by impaired VMAT function (Fig. 5c).

The toxic effect of FGFR1c-Fc saturated at $\sim 50 \%$ loss, raising the question of whether there are qualitatively different subtypes of DA neurons in the culture. Previous in vitro and in vivo studies in animal models show that calbindin-expressing DA neurons are more resistant to toxic DA analogues [6-OHDA (Gerfen et al., 1985) and MPTP (German et al., 1992)]. Calbindin ${ }^{-}$neurons are also present in the human SNpc and these cells are differentially lost in PD (Fearnley and Lees, 1990; Yamada et al., 1990; Damier et al., 1999). Double staining with $\mathrm{TH}$ and calbindin antibodies was used to determine whether the calbindin ${ }^{-}$neurons show increased sensitivity to a short-term treatment with $1.5 \mu \mathrm{M}$ reserpine and $100 \mathrm{ng} / \mathrm{ml}$ FGFR1c-Fc. Calbindin ${ }^{-}$neurons were preferentially lost with increasing doses of the FGFR blocking reagent (Fig. $5 d, e$ ). These data show that it is the calbindin ${ }^{-}$neurons that are most dependent on FGF survival signals when function of the vesicular transporter is compromised.

\section{FGF-20 increases DA levels through activation of TH}

A simple strategy to counter DA toxicity would be to reduce DA levels. To examine whether FGF-20 reduces DA levels, DA content was measured with and without FGF-20 treatment. There was a significant increase in DA content $45 \mathrm{~min}$ after the application of FGF-20. This increase was blocked by the coapplication of PD98059, indicating that MAPK activation was required (Fig. $6 a$ ). The enzyme aromatic amino acid decarboxylase (AADC) converts the product of TH, L-DOPA, into DA. When AADC is inhibited, the level of L-DOPA directly measures TH activity. In cells treated with FGF-20 and the AADC inhibitor NSD-1015, there was a clear increase in L-DOPA that was blocked by PD98059 (Fig. 6b). These results suggest that FGF-20 treatment increases DA synthesis by activating TH.

Tyrosine hydroxylase activity is regulated by posttranslational modification. Three phosphorylation sites augment TH activity (Ser-19, Ser-31, and Ser-40) (Lindgren et al., 2000, 2002). Phosphorylation levels of all three Ser residues increased shortly after the application of FGF-20 (5 min) (Fig. 6c) and among those, the phospho-Ser-31 level was sustained up to 30 
min, whereas the levels of phospho-Ser-19 and Ser-40 declined after 15 min (Fig. 6c). The sustained elevation of phosphoSer-31 was blocked by PD98059. These results suggest that FGF-20 stimulates endogenous DA levels by elevating $\mathrm{TH}$ activity through MAPK-mediated Ser phosphorylation.

We next explored the kinetics of the effect of FGF-20 on DA levels. A brief (5 $\mathrm{min}$ ) exposure to FGF-20 did not increase DA levels, but after 45 min of incubation, extracellular DA levels increased 1.7 times $\left(n=4 ;{ }^{*} p=0.0032\right)$ (Fig. $\left.6 d\right)$. The increase was blocked by PD98059 (81.5 \pm $4.6 \%$ of the control, $n=4$ ), indicating that MAPK activation is responsible. The total DA and the released DA both increased with the same time course and to the same extent after FGF-20 treatment (Fig. 6d). FGF-20-induced DA release was observed in the presence of anisomycin, an inhibitor for translation, indicating that posttranslational modification is responsible for the increase (Fig. 6d). FGF-1, -2, -4, and -9 are known to stimulate $\mathrm{TH}$ expression via MAPK activation (Du and Iacovitti, 1995; Guo et al., 1998). Therefore, it is possible that FGF-20 further increases DA release at later time points because of stimulated TH expression. The application of quinpirole, a $\mathrm{D}_{2}$ autoreceptor agonist, inhibited DA release to the same level as in control (Fig. 6e), suggesting that the DA synthesized in response to FGF is packaged for vesicular release.

GDNF is known to acutely stimulate DA release by activating MAPK and inhibiting A-type potassium channels (Yang et al., 2001). To examine whether FGF-20 induced DA release by depolarizing cells in this way, we used high $\mathrm{K}^{+}$to evoke release in cells treated with FGF-20 and 4-AP to block voltage-dependent potassium channels. If K-channel inhibition was the only effect of FGF-20, 4-AP treatment should mimic treatment with the growth factor. High $\mathrm{K}^{+}$stimulation of FGF-20-treated cells increased DA levels 1.6-fold (Fig. 6f). This increase was blocked by PD98059 $(94.2 \pm 9.1 \%$ of the control; $n=4)$. When $\mathrm{Kv}$ channels were inhibited by 4-AP, DA release was also increased (Fig. $6 f$ ), but FGF-20 resulted in increased release above the levels seen with 4-AP (Fig. 6f). A 1 min pre-exposure to high $\mathrm{K}^{+}$was enough to reduce the evoked DA release to $16 \%$ of the control (Fig. 6g). The effect of FGF-20 on evoked DA release was completely blocked by AMPT, indicating the increased release of DA is dependent on increased DA synthesis (Fig. 6h). GDNF, acting through MAPK activation, acutely stimulates neuroactivity by
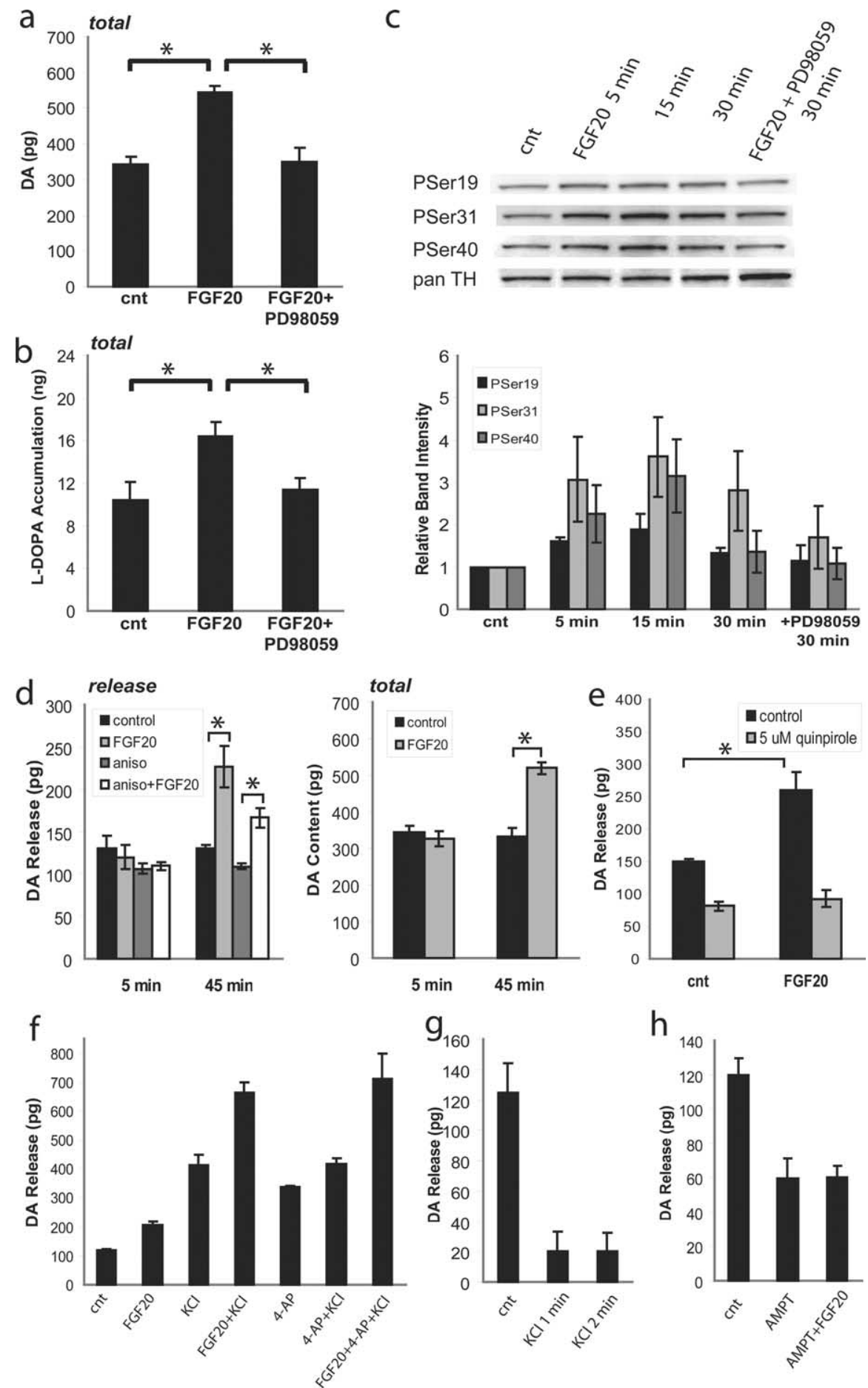

Figure 6. FGF-20 increases DA level. $\boldsymbol{a}$, Total DA level is increased by FGF-20. Neurons were incubated with $10 \mathrm{ng} / \mathrm{ml}$ of FGF-20 and $50 \mu \mathrm{M}$ PD98059 for $45 \min (n=4) .{ }^{*} p<0.05$. $\boldsymbol{b}$, L-DOPA accumulation induced by FGF-20 in the presence of $100 \mu \mathrm{M}$ NSD-1015 $(n=4)$. ${ }^{*} p<0.05$. c, Phosphorylation of Ser residues in TH by FGF-20. Shown are Western blot probed with anti-phospho Ser-19, Ser-31, and Ser-40 antibodies, and band intensities of phospho-Ser-19, Ser-31, and Ser-40. $n=3 . \boldsymbol{d}, \mathrm{DA}$ release (left) and total DA content (right) are both increased by FGF-20. Neurons were incubated with or without $10 \mathrm{ng} / \mathrm{ml}$ of FGF-20 for the indicated time before DA release measurements. To inhibit protein synthesis, cells were preincubated with $10 \mu \mathrm{m}$ anisomycin for 30 min before FGF-20 application. Note that the increase was not acute $(5 \mathrm{~min} ; n=4) .{ }^{*} p<0.05$. $e$, Effect of $D_{2}$ autoreceptor agonist, quinpirole. Preincubation with $10 \mathrm{ng} / \mathrm{ml} \mathrm{FGF-20} \mathrm{for} 45 \mathrm{~min}$ resulted in a significant increase in DA release, but no difference when release is measured in $5 \mu \mathrm{m}$ quinpirole $(n=4),{ }^{*} p<0.05$. $f$, Evoked DA release by $50 \mathrm{~mm} \mathrm{KCl}$ was also increased by FGF-20. Samples were incubated with $10 \mathrm{ng} / \mathrm{ml} \mathrm{FGF-20} \mathrm{for} 45 \mathrm{~min}$ before the DA release measurements. $10 \mathrm{~mm} 4-A P$ was applied ( $n=11,6,7,5,3,3$, and 3, respectively). $\boldsymbol{g}$, Effect of pre-exposure to high $\mathrm{K}^{+}$on DA release. DA release was compared in $50 \mathrm{~mm} \mathrm{KCl-MKB.} \mathrm{Only} 1 \mathrm{~min}$ of pre-exposure to $50 \mathrm{~mm} \mathrm{KCl}$ was enough to decrease DA release to $16 \%(n=3)$. $\boldsymbol{h}$, Effect of TH inhibition on the increased high $\mathrm{K}^{+}$stimulated DA release by FGF-20. The culture was incubated with $500 \mu \mathrm{M}$ AMPT for 20 min before the application of $10 \mathrm{ng} / \mathrm{ml}$ of FGF-20. DA release was compared in $50 \mathrm{~mm} \mathrm{KCl-MKB,} 45 \mathrm{~min}$ after the application of FGF-20 (control, AMPT, AMPT plus FGF-20; $n=5,8$, and 9, respectively). Error bars indicate SE. 
a
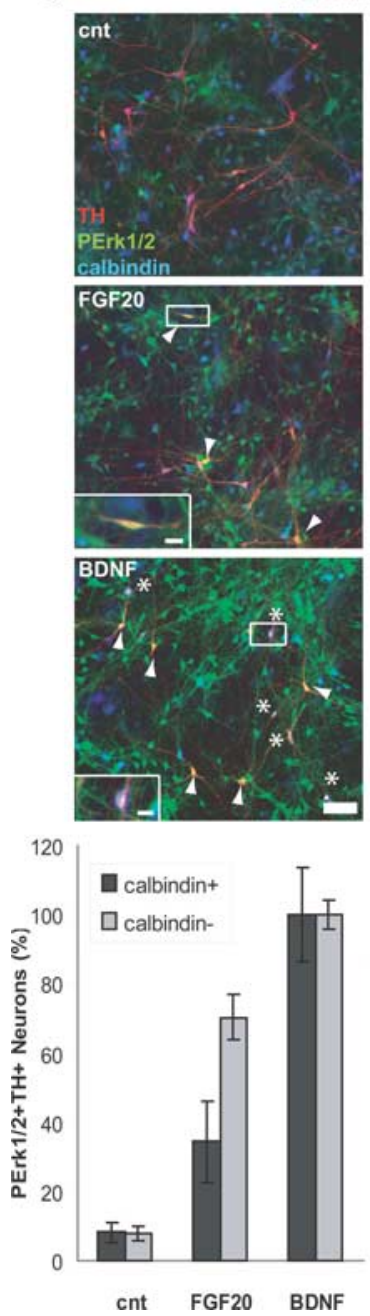

dissociated culture
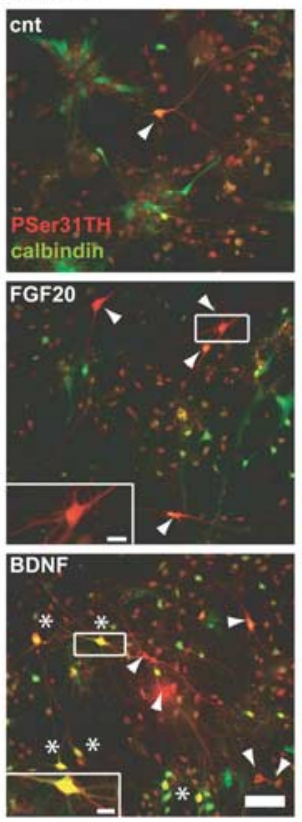

${ }^{120}$ a calbindin+

$\square$ calbindin-

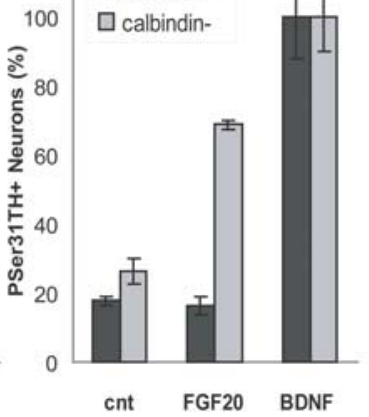

b
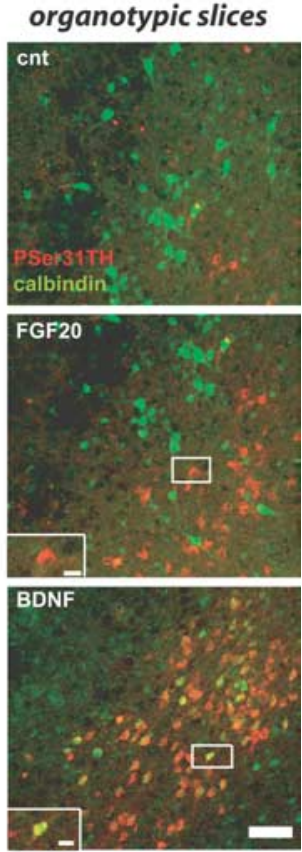

120

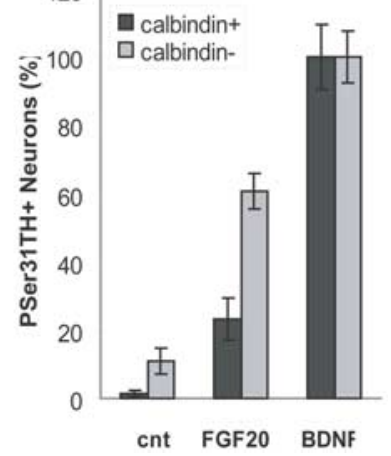

Figure 7. FGF-20 acts on calbindin ${ }^{-}$DA neurons. $\boldsymbol{a}$, Dissociated cultured neurons were stimulated by neurotrophins $(n=30)$. Left, Immunostaining with TH (red), phospho-Erk1/2 (green), and calbindin (blue). Right, Immunostaining with phospho-Ser-31 $\mathrm{TH}$ (red) and calbindin (green). Samples were incubated with $10 \mathrm{ng} / \mathrm{ml} \mathrm{FGF-20} \mathrm{(or} \mathrm{BDNF)} \mathrm{for} 10 \mathrm{~min} .{ }^{*}$ Calbindin ${ }^{+}$; arrowheads, calbindin ${ }^{-} \cdot \boldsymbol{b}$, Organotypic midbrain slices were stimulated by neurotrophins $(n=10)$. Immunostaining with phospho-Ser $31 \mathrm{TH}$ (red) and calbindin (green) is shown. Samples were incubated with $10 \mathrm{ng} / \mathrm{ml} \mathrm{FGF-20} \mathrm{(or} \mathrm{BDNF)} \mathrm{for} 45 \mathrm{~min}$. Scale bars, $50 \mu \mathrm{m}$. Insets, magnified images. Scale bars, $10 \mu \mathrm{m}$. Relative numbers of neurons are shown at the bottom. Calbindin ${ }^{-}$DA neurons were selectively activated by FGF-20. Error bars indicate SE.

inhibiting an A-type potassium channel (Yang et al., 2001). FGF-20 treatment elevates DA release but only after a delay, consistent with increased synthesis of the transmitter and an increase in the levels of DA poised for vesticular release.

\section{Calbindin ${ }^{-}$DA neurons preferentially respond to FGF-20 and express FGFR1}

In all the cell death assays discussed here, only a subset of DA neurons are lost. Our observations suggest that calbindin ${ }^{-}$DA neurons are preferentially sensitive to reserpine stress combined with FGF receptor blockade. To further explore this partial loss, neurons responding to growth factors were identified by phosphorylation of Erk1/2. The expression of $\mathrm{TH}$ and calbindin allowed identification of the neurons responding to growth factor stimulation. Triple immunostaining with $\mathrm{TH}$, calbindin, and phospho-Erk1/2 showed that BDNF induced Erk phosphorylation in almost all of the $\mathrm{TH}^{+}$neurons including calbindin ${ }^{+}$and calbindin ${ }^{-}$(Fig. 7a). In contrast, FGF-20 treatment favored Erk activation in calbindin ${ }^{-}$DA neurons.

The phosphorylation of Ser-31 of TH was used to ask whether cabindin ${ }^{-}$neurons show preferential $\mathrm{TH}$ activation in response to FGF treatment. In controls, few neurons were labeled with PSer31-TH antibodies. BDNF induced TH phosphorylation in both calbindin ${ }^{+}$and calbindin ${ }^{-}$ neurons (Fig. 7a). In contrast, FGF-20 induced phosphorylation of Ser-31 in calbindin $^{-}$neurons (Fig. 7a).

The analysis with PSer-TH immunostaining was also performed in organotypic slice cultures. Activation of TH by FGF-20 was preferentially observed in calbindin ${ }^{-}$neurons, whereas both calbindin $^{+}$and calbindin ${ }^{-}$neurons were activated by BDNF (Fig. 7b). Our results indicate that calbindin ${ }^{-}$neurons preferentially respond to FGF-20 both in dissociated and organotypic-slice cultures.

A simple explanation for the specific response of calbindin ${ }^{-}$neurons to FGF-20 is the specific expression of the receptor in those neurons. Immunostaining of adult midbrain sections with antiFGFR1 antibody showed that in the ventral tier of SNpc, calbindin ${ }^{-}$neurons express FGFR1, whereas in the dorsal tier, calbindin ${ }^{+}$neurons express low levels of FGFR1. This result supports the finding that calbindin ${ }^{-}$neurons preferentially respond to FGF-20 (Fig. 8a,b).

\section{Discussion}

The purpose of this study was to define the response of mature ventral midbrain DA neurons to FGF-20. Because DA transmission and reuptake play a central role in DA neuron survival, we set criteria for neuronal maturation: (1) developmental cell death, (2) morphological complexity, (3) formation of synaptic structure, and (4) functional regulation of DA release, and confirmed that DA neurons in tissue culture can fulfill these criteria. Using this culture system, we found two subtypes of DA neurons that are sensitive or insensitive to endogenous FGF (see supplemental material, available at www.jneurosci.org). The FGFsensitive neurons lack expression of calbindin, and FGF signaling was only important for survival when DA was present. FGF-20 rapidly activates the cytoplasmic kinases, PI3K and MAPK, and antiapoptotic events including phosphorylation of Bad and downregulation of Bax, which may explain the protective action. PI3K is known to induce phosphorylation of Bad (Datta et al., 1997). Bax expression can be activated by $\mathrm{p} 53$ (Miyashita and Reed, 1995). The decreased level of Bax in FGF-treated cells might be attributable to the induction of p53 degradation. FGF-20 activation occurred preferentially in calbindin ${ }^{-}$neurons in both dissociated and organotypic-slice cultures. Concomitantly, FGFR1 is selectively expressed in calbindin ${ }^{-}$neurons in adult SNpc. Therefore, it is likely that the properties of two types of neurons are conserved in vivo. FGFR signaling not only protects calbindin ${ }^{-}$neurons, but also activates $\mathrm{TH}$, resulting in increased levels of DA release. These results show that 
a
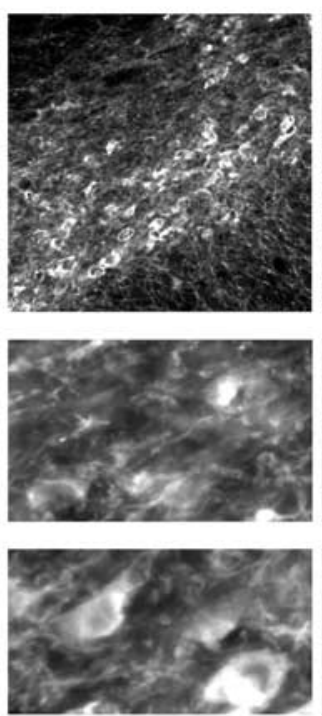

$\mathrm{TH}$
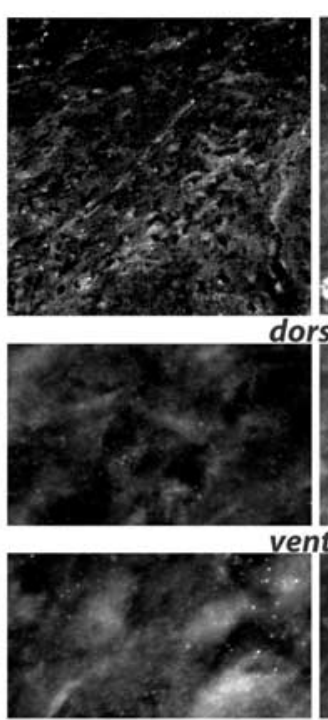

FGFR1 adult ventral midbrain

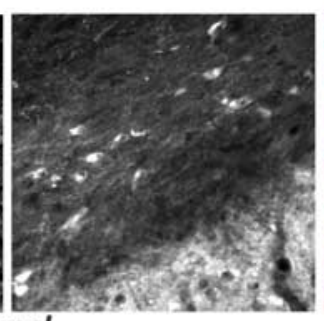

rsal

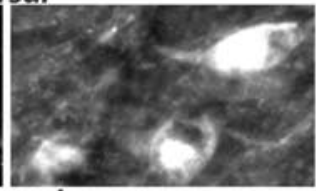

ntral

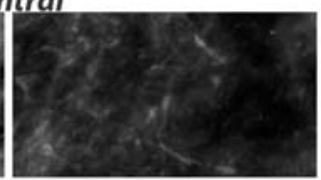

calbindin
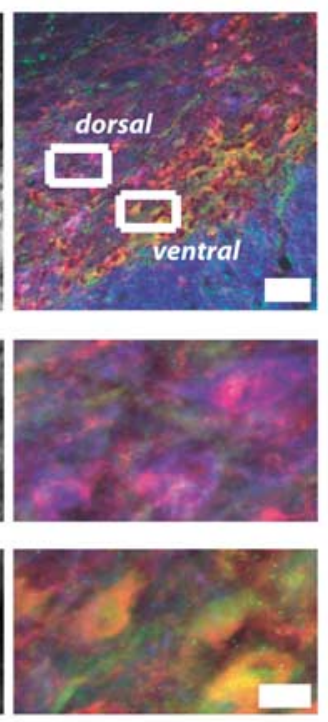

overlay b

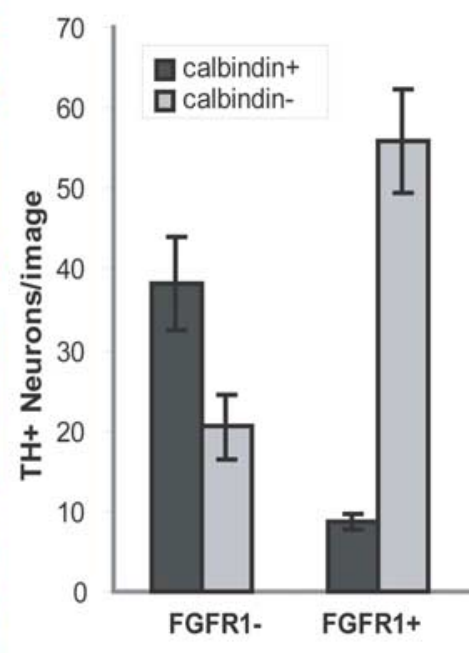

Figure 8. FGFR1 is highly expressed in calbindin ${ }^{-}$DA neurons. $a$, Adult midbrain slice was immunostained with TH (red), FGFR1 (green), and calbindin (blue). Scale bar, $50 \mu m$. Magnified images of dorsal region with calbindin ${ }^{+}$DA neurons and ventral region with calbindin ${ }^{-}$DA neurons were shown in bottom panels. Scale bar, $20 \mu \mathrm{m} . \boldsymbol{b}$, Numbers of neurons are shown ( $\left.n=10\right)$. Error bars indicate SE.

FGF triggers signaling events known to reduce oxidative stress and promotes DA functions in a subset of DA neurons.

In this study, survival of midbrain DA neurons was assessed in relation to functions of VMAT2 and DAT transporters. We demonstrate that in young neurons, low levels of DA are released from DAT but not through activity-triggered vesicle release. As a consequence, inhibition of VMAT2 did not show toxicity. In mature neurons, vesicle release of DA via neural activity and its efficient reuptake, and inhibition of release by $\mathrm{D}_{2}$ autoreceptor were all present. Under these conditions, a specific group of neurons are sensitive to FGF blockade and this vulnerability depends on DA levels. The VMAT2 blocker reserpine also puts these neurons at risk. When FGF signals are reduced, even a short-term exposure to reserpine is enough to cause loss of these neurons.

VMAT2 is not the only target of reserpine (Beck et al., 1988), but because cell death was blocked by inhibition of DA synthesis, neural activity, and DAT, it is clear that DA transmission and reuptake is a critical feature of survival in these cells and it is likely that the reserpine-induced toxicity is caused by VMAT2 inhibition rather than by some other mechanism. Treatment with reserpine decreases total DA content and nomifensine does not influence this effect, suggesting that the basal cytosolic DA levels are well maintained as shown previously (Mosharov et al., 2003). These results suggest that the toxicity of reserpine is not attributable to the chronic accumulation of cytosolic DA, but rather a local and transient exposure to DA. The high concentrations of DA achieved by DAT action after release would provide this type of stress. Short-term exposure to exogenous DA indeed caused loss of DA neurons. Our observations suggest that the contribution of DA recycling dynamics to oxidative stress can be studied in vitro.

In our work, calbindin ${ }^{-}$DA neurons specifically require FGF signaling to protect against an ongoing DA-dependent stress. Calbindin ${ }^{-}$DA neurons are enriched in the ventral tier of SNpc (or A9) and project to striatal patches. These neurons are at particular risk in PD, whereas DA neurons in ventral tegmental area (or A10) are predominantly calbindin ${ }^{+}$(Gerfen et al., 1987). In both rodent and primate adult midbrain, the levels of DAT mRNA (Sanghera et al., 1994; Haber et al., 1995) and DAT protein (Gonzalez-Hernandez et al., 2004) are higher in calbindin ${ }^{-}$ than in calbindin ${ }^{+}$DA neurons. In vivo studies both in rodents and primates show that the neurons of the rostromedial region of substantia nigra, the majority of which are calbindin ${ }^{+}$, express higher level of VMAT2 than the caudoventral regions of substantia nigra, the majority of which are calbindin ${ }^{-}$(GonzalezHernandez et al., 2004). Liang et al. (2004) have shown in PD patients, that the levels of VMAT2 are lower in neurons that express high levels of neuromelanin pigment, located in regions where calbindin immunoreactivity is poor (Damier et al., 1999). Calbindin $^{+}$DA neurons in our culture also showed higher VMAT2 and lower DAT than calbindin ${ }^{-}$DA neurons (data not shown). Combination of high DAT and low VMAT2 levels would result in higher oxidative stress in calbindin ${ }^{-}$DA neurons.

The central goal of our experiments was to determine whether FGF-20 played a neurotrophic role in DA neurons as suggested by genetic data in PD patients (van der Walt et al., 2004). The function of FGF-20 reported here supports the genetic data associating mutations in this gene with PD. These data also suggest that elevated presynaptic function and improved survival can be simultaneously achieved in the class of midbrain DA neuron at most risk in PD.

\section{References}

Abeliovich A, Schmitz Y, Farinas I, Choi-Lundberg D, Ho WH, Castillo PE, Shinsky N, Verdugo JM, Armanini M, Ryan A, Hynes M, Phillips H, Sulzer D, Rosenthal A (2000) Mice lacking alpha-synuclein display functional deficits in the nigrostriatal dopamine system. Neuron 25:239-252.

Acsadi G, Anguelov RA, Yang H, Toth G, Thomas R, Jani A, Wang Y, Ianakova E, Mohammad S, Lewis RA, Shy ME (2002) Increased survival and function of SOD1 mice after glial cell-derived neurotrophic factor gene therapy. Hum Gene Ther 13:1047-1059. 
Adams Jr JD, Chang ML, Klaidman L (2001) Parkinson's disease-redox mechanisms. Curr Med Chem 8:809-814.

Backman C, Rose GM, Hoffer BJ, Henry MA, Bartus RT, Friden P, Granholm AC (1996) Systemic administration of a nerve growth factor conjugate reverses age-related cognitive dysfunction and prevents cholinergic neuron atrophy. J Neurosci 16:5437-5442.

Baquet ZC, Gorski JA, Jones KR (2004) Early striatal dendrite deficits followed by neuron loss with advanced age in the absence of anterograde cortical brain-derived neurotrophic factor. J Neurosci 24:4250-4258.

Beck WT, Cirtain MC, Glover CJ, Felsted RL, Safa AR (1988) Effects of indole alkaloids on multidrug resistance and labeling of $\mathrm{P}$-glycoprotein by a photoaffinity analog of vinblastine. Biochem Biophys Res Commun 153:959-966.

Betarbet R, Sherer TB, MacKenzie G, Garcia-Osuna M, Panov AV, Greenamyre JT (2000) Chronic systemic pesticide exposure reproduces features of Parkinson's disease. Nat Neurosci 3:1301-1306.

Carvelli L, Moron JA, Kahlig KM, Ferrer JV, Sen N, Lechleiter JD, LeebLundberg LM, Merrill G, Lafer EM, Ballou LM, Shippenberg TS, Javitch JA, Lin RZ, Galli A (2002) PI 3-kinase regulation of dopamine uptake. J Neurochem 81:859-869.

Choi-Lundberg DL, Lin Q, Chang YN, Chiang YL, Hay CM, Mohajeri H, Davidson BL, Bohn MC (1997) Dopaminergic neurons protected from degeneration by GDNF gene therapy. Science 275:838-841.

Choi-Lundberg DL, Lin Q, Schallert T, Crippens D, Davidson BL, Chang YN, Chiang YL, Qian J, Bardwaj L, Bohn MC (1998) Behavioral and cellular protection of rat dopaminergic neurons by an adenoviral vector encoding glial cell line-derived neurotrophic factor. Exp Neurol 154:261-275.

Connor B, Kozlowski DA, Schallert T, Tillerson JL, Davidson BL, Bohn MC (1999) Differential effects of glial cell line-derived neurotrophic factor (GDNF) in the striatum and substantia nigra of the aged Parkinsonian rat. Gene Ther 6:1936-1951.

Damier P, Hirsch EC, Agid Y, Graybiel AM (1999) The substantia nigra of the human brain. II. Patterns of loss of dopamine-containing neurons in Parkinson's disease. Brain 122 (Pt 8):1437-1448.

Datta SR, Dudek H, Tao X, Masters S, Fu H, Gotoh Y, Greenberg ME (1997) Akt phosphorylation of BAD couples survival signals to the cell-intrinsic death machinery. Cell 91:231-241.

Dauer W, Przedborski S (2003) Parkinson's disease: mechanisms and models. Neuron 39:889-909.

Ding YM, Jaumotte JD, Signore AP, Zigmond MJ (2004) Effects of 6-hydroxydopamine on primary cultures of substantia nigra: specific damage to dopamine neurons and the impact of glial cell line-derived neurotrophic factor. J Neurochem 89:776-787.

Dougan DF, Duffield AM, Duffield PH, Wade DN (1983) The effects of $(+)$-amphetamine, alpha-methyltyrosine, and alpha-methylphenylalanine on the concentrations of m-tyramine and alpha-methyl-mtyramine in rat striatum. Br J Pharmacol 80:309-314.

Du X, Iacovitti L (1995) Synergy between growth factors and transmitters required for catecholamine differentiation in brain neurons. J Neurosci 15:5420-5427.

Engele J, Bohn MC (1991) The neurotrophic effects of fibroblast growth factors on dopaminergic neurons in vitro are mediated by mesencephalic glia. J Neurosci 11:3070-3078.

Fahn S, Sulzer D (2004) Neurodegeneration and neuroprotection in Parkinson disease. NeuroRx 1:139-154.

Fearnley JM, Lees AJ (1990) Striatonigral degeneration. A clinicopathological study. Brain 113:1823-1842.

Fon EA, Pothos EN, Sun BC, Killeen N, Sulzer D, Edwards RH (1997) Vesicular transport regulates monoamine storage and release but is not essential for amphetamine action. Neuron 19:1271-1283.

Gerfen CR, Baimbridge KG, Miller JJ (1985) The neostriatal mosaic: compartmental distribution of calcium-binding protein and parvalbumin in the basal ganglia of the rat and monkey. Proc Natl Acad Sci USA 82:8780-8784.

Gerfen CR, Herkenham M, Thibault J (1987) The neostriatal mosaic: II. Patch- and matrix-directed mesostriatal dopaminergic and nondopaminergic systems. J Neurosci 7:3915-3934.

German DC, Manaye KF, Sonsalla PK, Brooks BA (1992) Midbrain dopaminergic cell loss in Parkinson's disease and MPTP-induced parkinsonism: sparing of calbindin-D28k-containing cells. Ann NY Acad Sci 648:42-62.

Gill SS, Patel NK, Hotton GR, O’Sullivan K, McCarter R, Bunnage M, Brooks
DJ, Svendsen CN, Heywood P (2003) Direct brain infusion of glial cell line-derived neurotrophic factor in Parkinson disease. Nat Med 9:589-595.

Goldberg MS, Pisani A, Haburcak M, Vortherms TA, Kitada T, Costa C, Tong Y, Martella G, Tscherter A, Martins A, Bernardi G, Roth BL, Pothos EN, Calabresi P, Shen J (2005) Nigrostriatal dopaminergic deficits and hypokinesia caused by inactivation of the familial Parkinsonism-linked gene DJ-1. Neuron 45:489-496.

Goldstein LS (2003) Do disorders of movement cause movement disorders and dementia? Neuron 40:415-425.

Gonzalez-Hernandez T, Barroso-Chinea P, De La Cruz Muros I, Del Mar Perez-Delgado M, Rodriguez M (2004) Expression of dopamine and vesicular monoamine transporters and differential vulnerability of mesostriatal dopaminergic neurons. J Comp Neurol 479:198-215.

Grossman SR, Perez M, Kung AL, Joseph M, Mansur C, Xiao ZX, Kumar S, Howley PM, Livingston DM (1998) p300/MDM2 complexes participate in MDM2-mediated p53 degradation. Mol Cell 2:405-415.

Guo Z, Du X, Iacovitti L (1998) Regulation of tyrosine hydroxylase gene expression during transdifferentiation of striatal neurons: changes in transcription factors binding the AP-1 site. J Neurosci 18:8163-8174.

Haber SN, Ryoo H, Cox C, Lu W (1995) Subsets of midbrain dopaminergic neurons in monkeys are distinguished by different levels of mRNA for the dopamine transporter: comparison with the mRNA for the D2 receptor, tyrosine hydroxylase and calbindin immunoreactivity. J Comp Neurol 362:400-410.

Hauptmann N, Grimsby J, Shih JC, Cadenas E (1996) The metabolism of tyramine by monoamine oxidase $\mathrm{A} / \mathrm{B}$ causes oxidative damage to mitochondrial DNA. Arch Biochem Biophys 335:295-304.

Henry JP, Botton D, Sagne C, Isambert MF, Desnos C, Blanchard V, RaismanVozari R, Krejci E, Massoulie J, Gasnier B (1994) Biochemistry and molecular biology of the vesicular monoamine transporter from chromaffin granules. J Exp Biol 196:251-262.

Hyman C, Hofer M, Barde YA, Juhasz M, Yancopoulos GD, Squinto SP, Lindsay RM (1991) BDNF is a neurotrophic factor for dopaminergic neurons of the substantia nigra. Nature 350:230-232.

Ichijo H (1999) From receptors to stress-activated MAP kinases. Oncogene 18:6087-6093.

Isacchi A, Bergonzoni L, Sarmientos P (1990) Complete sequence of a human receptor for acidic and basic fibroblast growth factors. Nucleic Acids Res 18:1906.

Jenner P (2003) Oxidative stress in Parkinson's disease. Ann Neurol 53 [Suppl 3]:S26-S36; discussion S36-S28.

Juorio AV, Boulton AA (1982) The effect of some precursor amino acids and enzyme inhibitors on the mouse striatal concentration of tyramines and homovanillic acid. J Neurochem 39:859-863.

Kirikoshi H, Sagara N, Saitoh T, Tanaka K, Sekihara H, Shiokawa K, Katoh M (2000) Molecular cloning and characterization of human FGF-20 on chromosome 8p21.3-p22. Biochem Biophys Res Commun 274:337-343.

Knusel B, Michel PP, Schwaber JS, Hefti F (1990) Selective and nonselective stimulation of central cholinergic and dopaminergic development in vitro by nerve growth factor, basic fibroblast growth factor, epidermal growth factor, insulin and the insulin-like growth factors I and II. J Neurosci 10:558-570.

Kouhara H, Hadari YR, Spivak-Kroizman T, Schilling J, Bar-Sagi D, Lax I, Schlessinger J (1997) A lipid-anchored Grb2-binding protein that links FGF-receptor activation to the Ras/MAPK signaling pathway. Cell 89:693-702.

Krieglstein K, Reuss B, Maysinger D, Unsicker K (1998a) Short communication: transforming growth factor-beta mediates the neurotrophic effect of fibroblast growth factor-2 on midbrain dopaminergic neurons. Eur J Neurosci 10:2746-2750.

Krieglstein K, Henheik P, Farkas L, Jaszai J, Galter D, Krohn K, Unsicker K (1998b) Glial cell line-derived neurotrophic factor requires transforming growth factor- $\beta$ for exerting its full neurotrophic potential on peripheral and CNS neurons. J Neurosci 18:9822-9834.

Kuzhikandathil EV, Yu W, Oxford GS (1998) Human dopamine D3 and D2L receptors couple to inward rectifier potassium channels in mammalian cell lines. Mol Cell Neurosci 12:390-402.

Larsen KE, Fon EA, Hastings TG, Edwards RH, Sulzer D (2002) Methamphetamine-induced degeneration of dopaminergic neurons involves autophagy and upregulation of dopamine synthesis. J Neurosci 22:8951-8960. 
Liang CL, Nelson O, Yazdani U, Pasbakhsh P, German DC (2004) Inverse relationship between the contents of neuromelanin pigment and the vesicular monoamine transporter-2: human midbrain dopamine neurons. J Comp Neurol 473:97-106.

Lin LF, Doherty DH, Lile JD, Bektesh S, Collins F (1993) GDNF: a glial cell line-derived neurotrophic factor for midbrain dopaminergic neurons. Science 260:1130-1132.

Lindgren N, Xu ZQ, Lindskog M, Herrera-Marschitz M, Goiny M, Haycock J, Goldstein M, Hokfelt T, Fisone G (2000) Regulation of tyrosine hydroxylase activity and phosphorylation at $\operatorname{Ser}(19)$ and $\operatorname{Ser}(40)$ via activation of glutamate NMDA receptors in rat striatum. J Neurochem 74:2470-2477.

Lindgren N, Goiny M, Herrera-Marschitz M, Haycock JW, Hokfelt T, Fisone G (2002) Activation of extracellular signal-regulated kinases 1 and 2 by depolarization stimulates tyrosine hydroxylase phosphorylation and dopamine synthesis in rat brain. Eur J Neurosci 15:769-773.

Martinez-Serrano A, Bjorklund A (1996) Protection of the neostriatum against excitotoxic damage by neurotrophin-producing, genetically modified neural stem cells. J Neurosci 16:4604-4616.

Mitchell JD, Wokke JH, Borasio GD (2002) Recombinant human insulinlike growth factor I (rhIGF-I) for amyotrophic lateral sclerosis/motor neuron disease. Cochrane Database Syst Rev 3:CD002064.

Miyashita T, Reed JC (1995) Tumor suppressor p53 is a direct transcriptional activator of the human bax gene. Cell 80:293-299.

Moron JA, Zakharova I, Ferrer JV, Merrill GA, Hope B, Lafer EM, Lin ZC, Wang JB, Javitch JA, Galli A, Shippenberg TS (2003) Mitogen-activated protein kinase regulates dopamine transporter surface expression and dopamine transport capacity. J Neurosci 23:8480-8488.

Mortensen OV, Amara SG (2003) Dynamic regulation of the dopamine transporter. Eur J Pharmacol 479:159-170.

Mosharov EV, Gong LW, Khanna B, Sulzer D, Lindau M (2003) Intracellular patch electrochemistry: regulation of cytosolic catecholamines in chromaffin cells. J Neurosci 23:5835-5845.

Ohmachi S, Watanabe Y, Mikami T, Kusu N, Ibi T, Akaike A, Itoh N (2000) FGF-20, a novel neurotrophic factor, preferentially expressed in the substantia nigra pars compacta of rat brain. Biochem Biophys Res Commun 277:355-360.

Ohmachi S, Mikami T, Konishi M, Miyake A, Itoh N (2003) Preferential neurotrophic activity of fibroblast growth factor-20 for dopaminergic neurons through fibroblast growth factor receptor-1c. J Neurosci Res 72:436-443.

Ong SH, Hadari YR, Gotoh N, Guy GR, Schlessinger J, Lax I (2001) Stimulation of phosphatidylinositol 3-kinase by fibroblast growth factor receptors is mediated by coordinated recruitment of multiple docking proteins. Proc Natl Acad Sci USA 98:6074-6079.

Otto D, Unsicker K (1990) Basic FGF reverses chemical and morphological deficits in the nigrostriatal system of MPTP-treated mice. J Neurosci 10:1912-1921.

Prolla TA, Mattson MP (2001) Molecular mechanisms of brain aging and neurodegenerative disorders: lessons from dietary restriction. Trends Neurosci 24:S21-S31.

Sanghera MK, Manaye KF, Liang CL, Lacopino AM, Bannon MJ, German DC (1994) Low dopamine transporter mRNA levels in midbrain regions containing calbindin. NeuroReport 5:1641-1644.

Shen J, Cookson MR (2004) Mitochondria and dopamine: new insights into recessive parkinsonism. Neuron 43:301-304.

Sherer TB, Betarbet R, Stout AK, Lund S, Baptista M, Panov AV, Cookson MR, Greenamyre JT (2002) An in vitro model of Parkinson's disease: linking mitochondrial impairment to altered $\alpha$-synuclein metabolism and oxidative damage. J Neurosci 22:7006-7015.

Shults CW, Ray J, Tsuboi K, Gage FH (2000) Fibroblast growth factor-2producing fibroblasts protect the nigrostriatal dopaminergic system from 6-hydroxydopamine. Brain Res 883:192-204.

Slevin JT, Gerhardt GA, Smith CD, Gash DM, Kryscio R, Young B (2005) Improvement of bilateral motor functions in patients with Parkinson disease through the unilateral intraputaminal infusion of glial cell linederived neurotrophic factor. J Neurosurg 102:216-222.

Sulzer D, Sonders MS, Poulsen NW, Galli A (2005) Mechanisms of neurotransmitter release by amphetamines: a review. Prog Neurobiol 75:406-433.

Suter-Crazzolara C, Unsicker K (1996) GDNF mRNA levels are induced by FGF-2 in rat C6 glioblastoma cells. Brain Res Mol Brain Res 41:175-182.

Tuszynski MH, U HS, Amaral DG, Gage FH (1990) Nerve growth factor infusion in the primate brain reduces lesion-induced cholinergic neuronal degeneration. J Neurosci 10:3604-3614.

Tuszynski MH, Thal L, Pay M, Salmon DP, U HS, Bakay R, Patel P, Blesch A, Vahlsing HL, Ho G, Tong G, Potkin SG, Fallon J, Hansen L, Mufson EJ, Kordower JH, Gall C, Conner J (2005) A phase 1 clinical trial of nerve growth factor gene therapy for Alzheimer disease. Nat Med 11:551-555.

Ungerstedt U (1971) Postsynaptic supersensitivity after 6-hydroxydopamine induced degeneration of the nigro-striatal dopamine system. Acta Physiol Scand [Suppl] 367:69-93.

van der Walt JM, Noureddine MA, Kittappa R, Hauser MA, Scott WK, McKay R, Zhang F, Stajich JM, Fujiwara K, Scott BL, Pericak-Vance MA, Vance JM, Martin ER (2004) Fibroblast growth factor 20 polymorphisms and haplotypes strongly influence risk of Parkinson disease. Am J Hum Genet 74:1121-1127.

Wang LJ, Lu YY, Muramatsu S, Ikeguchi K, Fujimoto K, Okada T, Mizukami H, Matsushita T, Hanazono Y, Kume A, Nagatsu T, Ozawa K, Nakano I (2002) Neuroprotective effects of glial cell line-derived neurotrophic factor mediated by an adeno-associated virus vector in a transgenic animal model of amyotrophic lateral sclerosis. J Neurosci 22:6920-6928.

Wang YM, Gainetdinov RR, Fumagalli F, Xu F, Jones SR, Bock CB, Miller GW, Wightman RM, Caron MG (1997) Knockout of the vesicular monoamine transporter 2 gene results in neonatal death and supersensitivity to cocaine and amphetamine. Neuron 19:1285-1296.

Witkovsky P, Veisenberger E, Haycock JW, Akopian A, Garcia-Espana A, Meller E (2004) Activity-dependent phosphorylation of tyrosine hydroxylase in dopaminergic neurons of the rat retina. J Neurosci 24:4242-4249.

Yamada T, McGeer PL, Baimbridge KG, McGeer EG (1990) Relative sparing in Parkinson's disease of substantia nigra dopamine neurons containing calbindin-D28K. Brain Res 526:303-307.

Yang F, Feng L, Zheng F, Johnson SW, Du J, Shen L, Wu CP, Lu B (2001) GDNF acutely modulates excitability and A-type $\mathrm{K}^{+}$channels in midbrain dopaminergic neurons. Nat Neurosci 4:1071-1078.

Yeh BK, Igarashi M, Eliseenkova AV, Plotnikov AN, Sher I, Ron D, Aaronson SA, Mohammadi M (2003) Structural basis by which alternative splicing confers specificity in fibroblast growth factor receptors. Proc Natl Acad Sci USA 100:2266-2271.

Zuccato C, Ciammola A, Rigamonti D, Leavitt BR, Goffredo D, Conti L, MacDonald ME, Friedlander RM, Silani V, Hayden MR, Timmusk T, Sipione S, Cattaneo E (2001) Loss of huntingtin-mediated BDNF gene transcription in Huntington's disease. Science 293:493-498. 